\title{
Pre-Published version
}

\section{Published IN Science of the Total Environment 433 (2012) 398-417 BIOACCESSIBILITY OF TRACE ELEMENTS IN SOILS IN NORTHERN IRELAND}

\author{
Amy Barsby ${ }^{\mathrm{a}, \neq}$, Jennifer M. McKinley ${ }^{\mathrm{a}, *}$, Ulrich Ofterdinger ${ }^{\mathrm{b}}$, Mike Young ${ }^{\mathrm{c}}$, Mark R. Cave ${ }^{\mathrm{d}}$, \\ Joanna Wragg ${ }^{\mathrm{d}}$ \\ ${ }^{a}$ School of Geography, Archaeology and Palaeoecology, Queen's University Belfast, BT7 1NN, UK \\ ${ }^{b}$ EERC, School of Planning, Architecture and Civil Engineering, Queen's University Belfast, Belfast, BT9 5AG, \\ UK, u.ofterdinger@qub.ac.uk \\ ${ }^{c} G S N I$, Belfast, BT9 5BF, UK, \\ ${ }^{d} B G S$, Keyworth, Nottingham, NG12 5GG, UK
}

*Corresponding author. Tel: +44(0)2890973827; fax:+44(0)2890973212

E-mail address: j.mckinley@qub.ac.uk

${ }^{\ddagger}$ posthumously

Key words: Bioaccessibility, trace elements, soil, geochemistry, geostatistics 
Abstract:

Assessment of elevated concentrations of potentially toxic elements (PTE) in soils and the association with specific soil parent material have been the focus of research for a number of years. Risk-based assessment of potential exposure scenarios to identified elevated PTE concentrations has led to the derivation of site- and contaminant-specific soil guideline values ( $\mathrm{SGVs}$ ), which represent generic assessment criteria (GACs) to identify exceeded levels that may reflect an unacceptable risk to human health. A better understanding of the 'bioavailable' or 'bioaccessible' contaminant concentrations offers an opportunity to better refine contaminant exposure assessments. Utilizing a comprehensive soil geochemical dataset for Northern Ireland provided by the Tellus Survey (GSNI) in conjunction with supplementary bioaccessibilty testing of selected soil samples following the Unified BARGE Method, this paper uses exploratory data analysis and geostatistical analysis to investigate the spatial variability of pseudo-total and bioaccessible concentrations of $\mathrm{As}, \mathrm{Cd}, \mathrm{Co}, \mathrm{Cr} . \mathrm{Cu}, \mathrm{Ni}, \mathrm{Pb}, \mathrm{U}, \mathrm{V}$ and $\mathrm{Zn}$. The paper investigates variations in individual element concentrations as well as cross-element correlations and observed lithological/pedological associations. The analysis of PTE concentrations highlighted exceeded levels of GAC values for $\mathrm{V}$ and $\mathrm{Cr}$ and exceeded $\mathrm{SGV} / \mathrm{GAC}$ values for $\mathrm{Cd}, \mathrm{Cu}, \mathrm{Ni}, \mathrm{Pb}$, and $\mathrm{Zn}$. UBM testing showed that for some soil parent materials associated with elevated PTE concentrations e.g. the Antrim Lava Group with high Ni concentrations, the measured oral bioaccessible fraction was relatively low. For other soil parent materials with relatively moderate PTE concentrations, measured oral bioaccessible fraction was relatively high (eg. the Gala Sandstone Group of the Southern Uplands-Down Longford Terrain). These findings have implications for regional human health risk assessments for specific PTEs. 
Introduction

Elevated concentrations of potentially toxic elements (PTE) in soils, including trace metal concentrations have been the focus of research for a number of years, investigating the risk associated with elevated PTE concentrations to human health. These studies have included the assessment of elevated PTE levels due to human activity in the context of contaminated land scenarios ( Okorie et al., 2011; Sialelli et al., 2011; Gbefa et al., 2011; Morillo et al., 2007; Zhang, 2006; Hursthouse, 2001; Meunier et al., 2010) as well as studies investigating the natural geogenous occurrence of elevated PTE concentrations associated with specific soil parent material and soil forming processes (Jordan et al., 2007; Spijker, 2005; Lado et al., 2008; Zhang et al., 2008; Tipping et al., 2006).

Over the past years a risk-based approach with regard to the assessment of potential exposure scenarios to identified elevated PTE concentrations within the context of contaminated land assessments has been established in a number of countries (Rothstein et al., 2006). Within the $\mathrm{UK}$, this risk-based assessment is completed in accordance with guidance documents developed by the Environment Agency (EA) using the Contaminated Land Exposure Assessment (CLEA) model (Jeffries and Martin, 2009). The CLEA model allows the derivation of site- and contaminant-specific soil guideline values (SGVs), which represent generic assessment criteria (GAC) with regard to identified risks posed to human health by chronic exposure to contaminated soil. The developed SGVs are based on the comparison between predicted contaminant exposure levels and established Health Criteria Values (HGVs) for specific metabolic models. To this end, exceedence of the so-derived SGVs may reflect an unacceptable risk to human health. Currently, only a limited number of SGVs for different land-use scenarios have been issued by the EA, including SGVs for a number of inorganic $(\mathrm{Ni}$, As, Cd and Se) as well as organic contaminants (Martin et al., 2009a, 2009b; Morgan et al., 2009). In addition to these published SGV values, the Chartered Institute of Environmental Health (CIEH) and Land Quality Management Ltd. (LQM) published an additional set of GACs for inorganic PTEs including $\mathrm{Cr}-\mathrm{III} / \mathrm{Cr}-\mathrm{IV}, \mathrm{Cu}, \mathrm{V}$ and $\mathrm{Zn}$ utilizing the CLEA Model and 
following the EA SGV approach (Jeffries and Martin, 2009) in deriving the published GACs (Nathanail et al., 2009).

In a wider context, the discipline of Medical Geology comprises the assessment of deleterious effects to human health as well as animal and plant life from elevated PTE concentrations associated with variations in their natural abundance in soils and rocks or conversely their deficiency for the case of bionecessary elements (Davies et al., 2005). Investigating the linkage between PTE concentrations and observed health and animal welfare effects has a long history reaching back to as early as the Song Dynasty (1000 BC) in China, where lung problems related to crushing rocks and producing symptoms of lead poisoning were observed (Davies et al., 2005). A broad body of research in the field of medical geology has recognised a number of naturally occurring PTEs (Nordberg and Cherian, 2005) such as arsenic (As), cobalt (Co), chromium $(\mathrm{Cr})$, copper $(\mathrm{Cu})$, nickel $(\mathrm{Ni})$, lead $(\mathrm{Pb})$, vanadium $(\mathrm{V})$, uranium $(\mathrm{U})$ and zinc $(\mathrm{Zn})$ known to influence human disease burden by their respective deficiency or toxicity.

A number of comprehensive regional and national soil sampling programmes have been completed in the past across the UK in an effort to assess natural background element concentrations in soils. These include the G-Base surveys conducted by the British Geological Survey/BGS (Johnson and Breward, 2004), the UK Soil and Herbage Pollutant Survey (Barraclough, 2007) as well as regional surveys such as for Northern Ireland (Jordan et al. 2000). These surveys provide background soil concentrations for a range of PTEs on varying sampling densities and targeting specific soil depths. With regard to available soil geochemical data across Northern Ireland, the Tellus Survey (Smyth, 2007) completed 2004-2006 provides a unique dataset combining comprehensive spatial soil sampling coverage with an extensive suite of soil geochemical analysis. In particular, since the soil parent geology across Northern Ireland covers a large variety of rock and associated soil types, typical for the geological and pedological conditions across the UK (Jordan et al., 2007), the Tellus data set provides the basis for a comprehensive study with relevancy for the whole of the UK.

Common to both the wider investigation of human health and welfare effects associated with naturally occurring variations in PTE concentrations and the specific assessment of 
anthropogenic contaminated land exposure scenarios to human health, is the underlying assessment of source-pathway-receptor linkages.

With regard to the assessment of soil borne PTE sources, several studies have demonstrated the difficulty in determining actual total PTE soil source concentrations (Pyle et al., 1996; Scancar et al., 2000; Marcos et al., 2011, Bonnard and Bour, 2008). Depending on physico-chemical soil conditions, specific PTE species and complexes, present in the soil and relevant for the exposure assessment may not be adequately represented in the results of individual laboratory analysis techniques and results provided by different soil analytical techniques and associated sample preparation and extraction procedures. Hence such laboratory analysis results may rather be regarded as pseudo-total concentrations (Ure, 1996; Gupta et al., 1996) within the limitations of the specific analytical methodology applied.

In addition to analytical difficulties in assessing soil source concentrations, the actual contaminant exposure to human receptors along identified pathways and thus associated health effects will furthermore depend on the actual physiological uptake of the contaminant. This 'bioavailable' fraction of the pseudo-total PTE soil concentration is in turn dependent on the fraction, which is 'bioaccessible' along an identified exposure pathway (Ruby, 2004). With regard to oral intake as a significant PTE exposure pathway in environmental exposure scenarios, this bioaccessible fraction refers to the PTE fraction released in the gastro-intestinal (GI) tract by digestive juices, thus representing the maximum contaminant concentration available for intestinal absorption (Cave et al., 2011). Ingestion bioaccessibility is only one of the exposure paths and a risk assessment includes inhalation of dust, consumption of local vegetables and skin absorption. In the case of the PTE soil concentrations looked at in this study, the ingestion path is usually the most important.

A better understanding of the 'bioavailable' or 'bioaccesible' contaminant concentrations offers an opportunity to better refine contaminant exposure assessments and thus to more effectively target remedial efforts and health/welfare protection measures, as recognized by local regulators and practitioners across England and Wales (Latawiec at al., 2010). UK Guidance reflects this 
opportunity for refinement in facilitating the incorporation of bioaccessibility data into the CLEA modelling process (Jeffries and Martin, 2009).

Since the assessment of 'bioavailable' contaminant concentrations with regard to human health effects relies principally on in vivo experiments, commonly affected by ethical constraints and the need for large financial resources, considerable research effort has been focused over the past years on developing reproducible laboratory methods to determine the bioaccessible fraction of soil-borne contaminants (Wragg and Cave, 2003; Van de Wiele et al., 2007). A number of in-vitro methods as laboratory analogues for the human gut have been developed in the past including a number of variants of Physiological Based Extraction Tests (PBET) (Ruby et al., 1996) and benchmarked against available animal in vivo studies. Furthermore, in an effort to make bioaccessibility assessments more easily comparable and reproducible, interlaboratory comparison studies have been completed between various developed methodologies (Wragg and Cave, 2003). One of the more widely accepted PBET methods for assessing the bioaccessibility of inorganic PTEs along the oral exposure route, which has emerged over the past years and, which has been successfully benchmarked against available in vivo experiments, was developed by the BioAccessability Research Group of Europe (BARGE; BARGE INERIS, 2011), providing bioaccessible PTE concentrations for both the gastric and gastro-intestinal phases.

This paper utilizes the unique soil geochemical data set provided by the Tellus Survey for Northern Ireland in conjunction with supplementary bioaccessibilty testing of selected soil samples following the Unified BARGE Method (BARGE INERIS, 2011) in order to investigate the spatial variability of pseudo-total and bioaccessible concentrations of $\mathrm{As}, \mathrm{Cd}, \mathrm{Co}, \mathrm{Cr}, \mathrm{Cu}$, $\mathrm{Ni}, \mathrm{Pb}, \mathrm{U}, \mathrm{V}$ and $\mathrm{Zn}$. In doing so, this paper will investigate variations in individual element concentrations as well as cross-element correlations and observed lithological/pedological associations. 
Materials and methods

\subsection{Soil Geochemical Data}

A number of soil geochemical surveys have been completed in the past across Northern Ireland for varying aims and objectives such as agriculture or mineral exploration. These surveys were completed with varying sampling densities and methodologies as well as specific analytical suites completed on collected soil samples. Relevant regional surveys completed in the past include the 1987-1997 Soil Atlas of Northern Ireland survey by the Department of Agriculture and Rural Development-DARD (Jordan et al., 2000) and the UK Soil and Herbage Pollutant Survey (Barraclough, 2007) covering England, Scotland, Wales and Northern Ireland.

A comprehensive soil geochemical dataset for Northern Ireland was added to the above information by the Tellus Project completed 2004-2006 (Smyth, 2007). The Tellus Project represents the most concentrated geological mapping project ever undertaken in Northern Ireland. The project was carried out by the Geological Survey of Northern Ireland (GSNI) and was funded by The Department for Enterprise, Trade and Investment (DETINI) and The Rural Development Programme through the Northern Ireland Programme for Building Sustainable Prosperity. The Tellus project comprised two concurrent parts, an airborne geophysical survey which collected data on magnetic fields, electrical conductivity and radioactivity and a ground based geochemical survey which collected soil and stream sediment as well as stream water samples. Regional 'rural' soil samples were collected on a grid of one sample site every $2 \mathrm{~km}^{2}$ across rural areas of Northern Ireland. A parallel 'urban' soil sampling programme at a sample density of 4 sites per $\mathrm{km}^{2}$ was completed across a number of selected urban areas across Northern Ireland. The rural soil samples collected at each sampling site included a surface soil sample collected from $5 \mathrm{~cm}$ to $20 \mathrm{~cm}$ below ground level (discarding surface organic litter and root zone where present) and a deep soil sample collected from $25 \mathrm{~cm}$ to $50 \mathrm{~cm}$ below ground level. The samples collected at each site represent a composite sample of five auger abstractions (completed with hand-held auger) at corner points and centre of a $20 \mathrm{~m} \times 20 \mathrm{~m}$ 
sampling square. Collected rural soil samples were disaggregated prior to sieving to a $<2 \mathrm{~mm}$ fraction and a representative sub-sample was obtained and milled for subsequent chemical analysis. Further details on the Tellus soil sampling programme, sampling methodology and sample preparation including quality control procedures are summarized in Smyth (2007). This paper focuses on the rural soil geochemical data set collated by the Tellus Project comprising a total of 6,862 soil samples.

As part of the Tellus Project, the collected rural soil samples were analysed for a range of up to 50 determinants. The completed chemical soil analysis with relevance for this paper completed for each soil samples included:

- Pressed pellet X-Ray Fluorescent Spectrometry (XRF) for determination of major oxides and trace elements using Wavelength Dispersive XRF Spectrometry (WD-XRF) and Energy Dispersive/Polarised XRF Spectrometry (ED-XRF); completed at British Geological Survey (BGS), Keyworth, Nottingham

- Aqua Regia digest of 1g sub-sample with subsequent analysis by Inductively Coupled Plasma-Mass Spectrometry (ICP-MS) and Inductively Coupled Plasma-Optical Emission Spectrometry (ICP-OES) for determination of trace elements; completed at SGS Laboratories (Toronto).

Table1 provides the detection limit and applied methodology for individual elements considered in this paper as analysed by XRF and ICP-OES/ICP-MS, respectively. Further details on laboratory methods employed, instrumentation and reagents and quality control procedures are summarized in Smyth (2007).

\subsection{Bioaccessibility Testing}

\subsubsection{Selection of Study Dataset for Bioaccessibility Testing}

The Tellus Project provides a comprehensive dataset of pseudo-total element concentrations in soils (by ICP-MS/OES and XRF, respectively) across Northern Ireland. In order to assess the bioaccessible concentrations of selected PTEs (as listed in Table 1), a subset of archived surface 
soil samples from the original rural soil sampling programme of the Tellus Project were selected for a smaller 'study' subset and for subsequent bioaccessibility testing.

The soil samples selected for the study subset were chosen to represent a broad spatial and lithological/pedological coverage across the region covered by the Tellus soil sampling survey. In order to minimize potential sampling bias in assembling the study sample subset it was decided that the most unbiased but representative approach to the selection of soil samples was based on soil and lithological classification (Jordan et al., 2000). Northern Ireland represents an unusual diversity of geology for such a small area (Fig. 1). The range of rocks presented forms a stratigraphic record which commences in the Mesoproterozoic (comprising deformed and metamorphosed sedimentary and volcanic rocks formed at least 600 million years ago) and includes examples of all geological systems up to and including the Palaeogene (comprising basalt lavas and lacustrine sedimentary rocks formed between circa 55 and 62 million years ago; Mitchell, 2004). The basement rocks of Northern Ireland can be partitioned into three major terrains. Oldest exposed Dalradian rocks constitute the northern terrain which can be traced across to the Highlands of Scotland. The Tyrone Igneous Complex with inliers of fossiliferous Ordovican and Silurian sedimentary rocks form the central terrain, an extension of the Midland Valley terrain of Scotland. Continental Devonian red-bed sediments and marine Carboniferous sedimentary rocks overlie the basement complex in the southwest of the region. The Southern Uplands-Down Longford Terrain is composed of Ordovician and Silurian rocks with the younger intrusive Newry Igneous Complex. In the northwest surface rocks of the Antrim Plateau are composed of Palaeogene basalt lava with underlying Permian, Triassic, Jurassic and Cretaceous rocks exposed at the margins. The last 100,000 years of the Northern Ireland's history involves the advance of ice sheets and their meltwaters. As a result, at least $80 \%$ of bedrock is covered by superficial deposits such as glacial till and post-glacial alluvium and peat (summarised from Mitchell, 2004). The most appropriate sampling strategy adopted for this study ensured that each of the 33 different soil parent categories included at least one sample, with additional samples included proportional to the total area covered by individual soil categories. Further consideration was given to ensure that archived samples contained sufficient material for carrying out the subsequent bioaccessibility testing. In total, 91 soil 
samples comprise the study sample subset. Figure 1 illustrates the subset sampling locations, scattered across Northern Ireland.

\subsubsection{Laboratory Bioaccessibility Testing}

To determine bioaccessible concentrations of selected inorganic PTEs (as listed in Table 1), the unified BARGE method (UBM) Version 14 (Wragg et al., 2009, 2011) was applied. As outlined above the unified BARGE method represents a widely accepted and in vivo validated PBET method for the determination of inorganic contaminant bioaccessibility for the human oral exposure route to soil contaminants. The UBM tests were carried out at the BGS laboratories, Keyworth Nottingham, following the UBM standard procedure (BARGE INERIS, 2011).

In principle, the UBM provides a laboratory analogue for the human digestive system (simulation of saliva, gastric and small intestinal phases) using synthetic fluids (saliva, gastric fluid, duodenal fluid and bile This results in the collection of two samples per soil under investigation, a 'stomach' sample which is produced after one hour agitation with saliva and gastric fluids and a 'stomach \& intestine' sample which is collected after one hour agitation with saliva and gastric fluid followed by four hours agitation with duodenal fluid and bile. BARGE INERIS (2011) and Wragg et al, 2011 provide further details of the testing protocol, including a schematic of the test methodology, the required testing equipment and reagents as well as step-by-step guidance on sample preparation and preparation of digestive fluids and modifications to the methodology since its inception by the BARGE network. Bioaccessible PTE concentrations were measured by ICP-MS on the extracted samples following the simulation of the gastric and gastric-intestinal extraction phase, respectively. The bioaccessibility extracts were analysed for trace metal contents using an Agilent $7500 \mathrm{cx}$ ICPMS The standard operating conditions were as follows: RF power $1550 \mathrm{~W}$; gas flow rates, coolant $151 \mathrm{~min}^{-1}$, auxiliary $0.81 \mathrm{~min}^{-1}$, nebulizer $0.851 \mathrm{~min}^{-1}$, make-up gas $0.251 \mathrm{~min}^{-1}$ and collision cell gas He $5.5 \mathrm{ml} \mathrm{min}^{-1}$. An internal standard solution was added via a t-piece to the sample stream containing Sc, Ge, Rh, In, Te and Ir, giving approximate signal sensitivity of greater $200 \mathrm{k}$ cps. Data was acquired in peak jump mode with an acquisition of $3 \times 30 \mathrm{~s}$. 
Calibration standards were matrix matched to the extract. A total of 91 soil samples within the study data set (dried and sieved $<250 \mu \mathrm{m}$ ) were tested applying the UBM test. For every ten soil samples analysed from the study subset, a duplicate test soil, a standard control soil (BGS 102; Wragg et al., 2009) and a blank (no soil) were included in the tested sample batch.

The bioaccessible fraction (BAF) of selected PTEs for individual samples was calculated using the determined bioaccessible concentration from the UBM test $\left(C_{b}\right)$ and the pseudo-total PTE concentration in the soil sample as provided by the Tellus project data base $\left(C_{p t}\right)$ :

$B A F[\%]=\frac{C_{b}\left[m g k g^{-1}\right]}{C_{p t}\left[m g k g^{-1}\right]} \times 100$

Equation 1

As the BAF is commonly used in the context of human health risk assessments, the BAF is calculated for individual samples using the highest bioaccessible PTE concentration of the respective two digestive extracts (gastric or gastric-intestinal) from the UBM test in a conservative approach. For the purposes of the discussion in this paper, the BAF for both individual digestive extracts (gastric or gastric-intestinal) was calculated and presented.

\subsubsection{Quality Control}

The quality control (QC) of the analysis was monitored by carrying out replicate analyses of BGS 102, a commercially available guidance soil, prepared by the BGS, specifically for bioaccessibility studies (Wragg et al, 2009). At present there are no certified values for the bioaccessibility of PTEs in reference materials however, the quality control material used in this study has been the subject of an international inter-laboratory trial and other studies (Broadway et al. 2010; Wragg et al. 2003; 2009; 2011), which have generated the consensus values against which the data from this study have been assessed. Within every batch of a maximum of ten soil samples from the study subset, one duplicate soil sample, one quality control soil and one blank were extracted.

Where published consensus values are available for BGS 102, average $\mathrm{As}, \mathrm{Cd}$ and $\mathrm{Pb}$ data for the current study $(n=10)$ were within the consensus values for the 'gastric' and the 'gastro- 
intestinal' phases of the UBM reported by Wragg et al. (2009), of $4.5 \pm 1.3 \mathrm{mg} \mathrm{kg}^{-1}$ and $5.4 \pm$ $2.4 \mathrm{mg} \mathrm{kg}^{-1}, 0.3 \pm 0.17$ and $0.59 \pm 0.53 \mathrm{mg} \mathrm{kg}^{-1}$, and $12.8 \pm 6.0$ and $3.1 \pm 4.4 \mathrm{mg} \mathrm{kg}^{-1}$, respectively. The average $\mathrm{Cr}$ data returned for the current study $(\mathrm{n}=10)$ was within the consensus values of $41 \pm 1$ and $5.8 \pm 3.8 \mathrm{mg} \mathrm{kg}^{-1}$ for the 'gastric' and the 'gastro-intestinal' phase, respectively as reported by Broadway et al. (2010). The average quality control data for BGS 102 for Ni and Zn were compared with the in-house BGS dataset generated by BGS research projects (Northampton, Swansea and T/Humber) which has not yet been published, but is monitored as part of a larger BGS database. Sample results for both of these PTE were within the BGS consensus values of $13.0 \pm 1.2 \mathrm{mg} \mathrm{kg}^{-1}$ and $10.0 \pm 0.70 \mathrm{mg} \mathrm{kg}^{-1}$ and $39.6 \pm 3.2$ $\mathrm{mg} \mathrm{kg}^{-1}$ and $7.8 \pm 3.9 \mathrm{mg} \mathrm{kg}^{-1}$ for the 'gastric' and the 'gastro-intestinal' phases for $\mathrm{Ni}$ and $\mathrm{Zn}$, respectively. Comparison of the BGS 102 data for $\mathrm{Co}, \mathrm{Cu}$ and $\mathrm{V}$ against the in-house generated values indicated that the data for this study were within the 'gastric' and 'gastro-intestinal' consensus values of $10.4 \pm 1.7 \mathrm{mg} \mathrm{kg}^{-1}$ and $4.8 \pm 0.5 \mathrm{mg} \mathrm{kg}^{-1}, 8.7 \pm 0.9 \mathrm{mg} \mathrm{kg}^{-1}$ and $9.0 \pm 0.9$ $\mathrm{mg} \mathrm{kg}^{-1}$ and $6.9 \pm 1.5 \mathrm{mg} \mathrm{kg}^{-1}$ and $3.0 \pm 0.5 \mathrm{mg} \mathrm{kg}^{-1}$, respectively.

\subsubsection{Laboratory Duplicates}

The data reported are individual sample concentrations and do not represent average concentrations of duplicate samples where applicable. For a number of individual soil samples, both 'gastric' and 'gastro-intestinal' phase replicates were completed. In total eleven samples were extracted in duplicate for the 'gastric' phase. Six of the eleven samples extracted in duplicate for the 'gastric' phase were also extracted in replicate for the 'gastro-intestinal' phase, with an additional 17 replicate samples (total of 23 replicate samples comprising 20 duplicates and three triplicates). Where samples were extracted in duplicate, repeatability was calculated as the absolute $\%$ difference and where replicate analysis has been carried out, repeatability is calculated as the \% RSD. The repeatability, as the average repeatability, was better than $10 \%$ for all PTE in the 'gastric' phase, except for Cd which was $10-20 \%$. For the 'gastro-intestinal' phase repeatability was $<20 \%$, except for $\mathrm{Pb}$ which was $<25 \%$. The higher $\mathrm{pH}$ of the gastrointestinal stage can often lead to precipitation of elements giving rise to poorer reproducibility than the stomach phase extract (Wragg et al., 2011). This should be taken into account when making interpretations using these data. 


\subsubsection{Laboratory Blanks}

Blank extractions were carried out at a frequency of $10 \%$ for both the 'gastric' and 'gastrointestinal' phases of the UBM test. An 'average blank' was calculated for each PTE of interest and its contribution compared to the corresponding 'average sample PTE concentration' across the samples in the data set. For the 'gastric' phase, all blank extractions for all PTE were below $5 \%$ of the 'average sample PTE' concentration, except $\mathrm{Zn}$ which was $<10 \%$ of the average sample $\mathrm{Zn}$ concentration. For the 'gastro-intestinal' phase, $\mathrm{Cd}, \mathrm{Pb}, \mathrm{Ni}, \mathrm{Cr}, \mathrm{Co}$ and $\mathrm{V}$ blank values were all $<10 \%$ of the 'average sample PTE concentration'. However, for As the average blank value was calculated as $11 \%$ of the 'average sample As concentration'. For Cu the blank value was $25 \%$ of the 'average sample $\mathrm{Cu}$ concentration' and for $\mathrm{Zn}$, the blank value was $80 \%$ of the 'average sample $\mathrm{Zn}$ concentration'.

The blank concentrations in the 'gastro-intestinal phase tend to be higher because of the addition of biological reagents (e.g. bile salts) which are not available in such high purity in as more standard analytical reagents and hence produce relatively high blanks for metals such as $\mathrm{Zn}$ and $\mathrm{Cu}$ but are usually low for $\mathrm{As}, \mathrm{Cd}$ and $\mathrm{Pb}$.

\subsection{Data Analysis}

Exploratory Data Analysis (EDA; Tukey, 1977) was carried out as an unbiased approach to assessing pseudo-total PTE concentrations as provided by the Tellus Survey (ICP-MS/OES and XRF data) as well as measured bioaccessible PTE concentrations as determined by the completed UBM tests. The EDA included boxplot analysis of individual element concentrations as well as correlation analysis between pseudo-total and respective bioaccessible PTE concentrations and cross-element correlation studies. The aim of the EDA was to explore the structure of the individual datasets and to evaluate potential cross-element associations and interactions. To further assess the spatial variability of observed PTE concentrations (pseudototal and bioaccessible) and their association with major bedrock type and soil type units within 
Northern Ireland, geospatial analysis techniques were applied to evaluate and visualise the collated data.

\subsection{Geostatistical Analysis}

Using the complete Tellus geochemical survey data (measured by XRF analysis), geostatistical techniques comprising variography and kriging, were used to analysis and map the spatial distribution of the PTE compounds ( $\mathrm{As}, \mathrm{Cd}, \mathrm{Co}, \mathrm{Cr}$. $\mathrm{Cu}, \mathrm{Ni}, \mathrm{Pb}, \mathrm{U}, \mathrm{V}$ and $\mathrm{Zn}$ ). The Theory of Regionalised Variables (Matheron, 1971) is the fundamental framework on which geostatistics is based. The classical framework for geostatistical analysis, adopted in this study, involved two stages: (i) estimation of the variogram and fitting a model to it and (ii) use of the variogram model coefficients for spatial prediction (kriging).

The variogram, a core tool in geostatistical analysis, was used for geostatistical spatial prediction. In this study the variogram was used to characterise spatial dependence in soil geochemistry. In simple terms, the variogram is estimated by calculating half the average squared difference between all the available paired measurements separated by a given lag tolerance (distance and direction). A mathematical model may be fitted to the experimental variogram and the coefficients of this model can be used for a range of geostatistical operations such as spatial prediction (kriging). In this study, variograms were estimated using Gstat version (Pebesma and Wesseling, 1998). Mathematical models were fitted to the experimental variograms using the weighted least squares functionality of Gstat. Models fitted to the experimental variograms were selected from a set of authorised models (McBratney and Webster, 1986). Parameters of the fitted models were used to provide information such as the maximum scale of spatial variation of the compounds of interest (Jensen et al., 1996; Gringarten and Deutsch, 2001; McKinley et al., 2004). The nugget, $\mathrm{c}_{0}$, represents the spatial variation at a finer scale than the sample spacing (Deutsch and Journel, 1998) and measurement error (Journal and Huijbregts, 1978). The structured component, $\mathrm{c}_{1}$, represents the spatially correlated variation (Lloyd, 2007). The sill or upper bound, $\mathrm{c}_{0}+\mathrm{c}_{1}$, is the a priori variance. The proportion of structure in the variation that has been resolved by the sampling can be determined by the nugget:sill ratio, i.e. the proportion of random to spatially structured 
variation at the scale of investigation. If the modeled variogram has a sill, the lag distance at which this is reached is known as the range of spatial dependence. This can be used to provide information on the scale of spatial variation or 'sphere of influence' of the PTE compounds. Kriging involves interpolation between sampled locations. Ordinary kriging (OK), which allows the mean of the measurements to vary spatially (Deutsch and Journel, 1998), was used in this study. A measure of uncertainty in the estimates was given by the kriging variance. The kriging variance is a measure of confidence in predictions and is a function of the form of the variogram, the sample configuration and the sample support (the area over which an observation is made; Journel and Huijbregts, 1978).

Results

\subsection{Data analysis results}

Table 2 provides a summary of the pseudo-total concentrations of individual PTEs for both the overall Tellus Dataset as well as the study sample subset. Table 2 furthermore provides summary concentrations from previous studies (Jordan et al., 2000; 2007) as well as measured bioaccessible PTE concentrations for the study sample subset. PTE concentrations are provided both as measured by ICP-MS/OES and by XRF analysis, where available. While individual pseudo-total As, Cd and Zn concentrations indicate a good alignment with normal probability distributions, the plots for the remaining PTEs indicate that these may not be regarded as normally distributed (Fig. 2). Non-normal distributions are commonly observed in soil geochemical data sets (Reimann and Filzmoser, 2000) and have also been reported for previous studies completed in Northern Ireland (Jordan et al., 2000; Jordan et al., 2007). To this end, Table 2 provides individual percentile values of measured PTE concentrations as a nonparametric summary of individual PTE concentration ranges. Other features that can be observed in Figure 2 are distinctive kinks in the normal probability plots for individual PTEs such as $\mathrm{Cr}, \mathrm{U}$ and $\mathrm{V}$ and to a less obvious degree for $\mathrm{Co}$ and $\mathrm{Ni}$ which are related to the presence of multiple populations within the respective PTE data. This in turn may reflect differential association with specific soil and parent rock types and/or an effect of varying abundance of specific PTE species as part of the measured total PTE concentrations (by XRF). 
With regard to the Tellus dataset and the study subset, Table 2 illustrates that PTE concentrations measured by XRF are commonly higher than respective PTE concentrations as measured by ICP-MS/OES highlighting that the Aqua Regia sample digestion in combination with subsequent ICP-MS/OES analysis was less efficient in providing representative PTE total concentrations. For some PTEs such as $\mathrm{Ni}$ and $\mathrm{Pb}$, this difference is less pronounced while for other elements such as $\mathrm{V}$ and $\mathrm{Cr}$ a 2-3 fold difference in total concentration by XRF and pseudo-total concentrations by ICP-MS/OES can be observed. Figure 3 furthermore illustrates these differences. To this end, total PTE concentrations as determined by XRF were used in the further data analysis for this paper.

Figure 4 illustrates the concentration ranges for individual PTEs within the overall Tellus data set (6,862 samples) and within the study sample sub-set (91 samples). The boxplots highlight that while the amount of outliers for individual PTE concentrations is greatly reduced within the study sample subset, the quartile ranges of the overall Tellus dataset are still well reflected within the study sample subset. Furthermore, Figure 4 shows that the individual PTE concentrations both in the Tellus dataset as well as the study subset are generally positively skewed, as can be expected with regard to the observed tailing of PTE concentration in the normal probability plots (Fig. 2). Non-normal, positively skewed distributions of untransformed soil geochemical data have been widely observed in previous studies (Davies et al., 2005; Mc Bratney et al., 1982; Reimann and Filzmoser, 2000), including for soil geochemical data collected across Northern Ireland in previous comprehensive studies (Jordan et al., 2007; Jordan et al., 2000). Outliers in the study subset for $\mathrm{Ni}, \mathrm{Cr}$ and $\mathrm{V}$ concentrations are predominantly related to samples derived from igneous/basalt soil parent material. Outlier values for $\mathrm{U}$ concentrations are related to samples derived from soil parent material typically associated with elevated $U$ concentrations, including shales, granites and limestones (Alloway, 2005).

With regard to the measured individual PTE concentrations, a number of outlier values for As, $\mathrm{Ni}, \mathrm{Cu}, \mathrm{Pb}, \mathrm{Zn}$ and $\mathrm{Cd}$ exceed the respective SGV or LQM/CIEH GAC value (Fig. 4), indicating potential risk to human health with regard to specific exposure/land use scenarios (Table 3). Furthermore, a large proportion of observed $\mathrm{V}$ and $\mathrm{Cr}$ concentrations within the 
interquartile range exceed the respective SGV/GAC values (assuming GAC for Cr-VI in a conservative approach). Strong positive correlations (Table 4 and Fig. 5) are observed between specific PTE abundances such as $\mathrm{Ni}$ with $\mathrm{Cr}$ and $\mathrm{Co}, \mathrm{Zn}$ with $\mathrm{Cd}, \mathrm{Cr}$ and $\mathrm{Co}$ as well as V with Co and $\mathrm{Cr}$.

\subsection{Geostatistical analysis results}

The parameters of the spherical models fitted to the experimental variograms, i.e. the nugget variance $\left(c_{0}\right)$, the sill variance of the spatially dependent component $(c)$ and the range $(a)$, for all PTEs are given in Table 5. The modelled variograms indicate spatial structure for all of the PTEs except $U$, which demonstrates a highly variable distribution across the region. Spatial structure at different ranges of correlation is observed for individual PTE concentrations. Shorter correlation distances $(\leq 20 \mathrm{~km})$ are indicated for $\mathrm{Cd}, \mathrm{Cr}$ and $\mathrm{Pb}$. Longer correlation distances $(>60 \mathrm{~km})$ are indicated for the PTEs of $\mathrm{Co}, \mathrm{Cu}, \mathrm{V}$ and $\mathrm{Zn}$. For PTE concentrations of As and $\mathrm{Cr}$ two distinctive correlation distances or ranges are observed (Table 5; shorter ranges 7-15 km, longer ranges $>40 \mathrm{~km}$ ). Spatial structure with two longer ranges is recorded for Ni concentrations $(\sim 50 \mathrm{~km}$ and $70 \mathrm{~km})$. The nugget:sill ratio $\left(c_{0}: c_{0}+c\right)$ varies from $14 \%(\mathrm{Ni})$ to $82 \%(\mathrm{~Pb})$ suggesting that for some of the PTEs (Table 5; $\mathrm{As}, \mathrm{Cr}, \mathrm{Cu}$ and $\mathrm{Pb}$ ) there is considerable unresolved variation at scales finer than the resolution of the Tellus survey (2 $\mathrm{km}^{2}$ ). The suggestion is that the spatial pattern of the PTEs is related to the distribution of geological and soil parent material. The presence of several scales of spatial structure may be related to the presence of multiple populations (more than one lithological/pedological source) within several of the data (most obvious for $\mathrm{Cr}$ and $\mathrm{Ni}$ ).

The parameters from variography were used for spatial prediction using kriging. The kriged outputs maps demonstrate lithological associations with the spatial distribution of PTE concentrations (Figs. 6 and 7). The presence of the basaltic lavas of the (Palaeogene) Antrim Lava Group has a strong control over the spatial distribution of several of the PTE concentrations. This is most evident for $\mathrm{Ni}, \mathrm{Cr}, \mathrm{Co}, \mathrm{V}$ and $\mathrm{Cu}$ and to a lesser degree for $\mathrm{Cd}$ and Zn. This concurs with the strong positive correlations (Table 4; Fig. 5) observed between PTE abundances of $\mathrm{Ni}$ with $\mathrm{Cr}$ and $\mathrm{Co}, \mathrm{Cr}$ and $\mathrm{Co}$, in addition to $\mathrm{V}$ with $\mathrm{Co}$ and $\mathrm{Cr}$. The implication is that PTE concentrations of $\mathrm{Ni}, \mathrm{Cr}, \mathrm{V}$ and $\mathrm{Cu}$ exceed the respective $\mathrm{SGV} / \mathrm{GAC}$ values for the Antrim basalt lavas potentially indicating a risk to human health with regard to specific 
exposure/land use scenarios. The spatial distribution of elevated concentrations of $\mathrm{Ni}, \mathrm{V}, \mathrm{Cr}, \mathrm{Co}$ and $\mathrm{Cu}$ suggested a secondary lithological control in the occurrence of these PTEs associated with the Southern Upland Terrain.

Arsenic is notably absent from basaltic lavas and overlying deposits. The distribution of As is more closely associated with sandstone and shales of the Midland valley and Southern Upland Terrains (Ordovician-Silurian) where concentrations of this PTE exceed SGV/GAC values. PTE concentrations of $\mathrm{Cd}, \mathrm{Zn}$ and $\mathrm{Pb}$ show outlier areas which exceed the respective SGV or LQM/CIEH GAC value but do not closely correspond to specific lithological and pedological associations.

\subsection{UBM bioacessibility testing results}

The results of the UBM bioacessibility tests completed on the study sample subset are summarized in Table 6. The results indicate that while the bioaccessible concentrations for As and $\mathrm{Cu}$ are similar for both the gastric and gastro-intestinal phase, for the majority of PTEs considered in this study, bioaccessible concentrations were significantly higher for the digestive extracts from the gastric phase. As a further measure of the bioaccessibility of individual PTEs within the study subset, the bioaccessible fraction (BAF) was calculated following Equation 1 for each of the samples within the study subset. Table 6 summarises the percentile values across the calculated BAFs for individual PTEs.

Figure 8 and Table 7 illustrate the correlation between measured individual pseudo-total PTE concentrations and their respective bioaccessible concentrations following the UBM test. Correlated PTEs include $\mathrm{Cd}, \mathrm{Zn}, \mathrm{As}, \mathrm{Pb}, \mathrm{Cr}, \mathrm{U}$ and $\mathrm{Co}$ for both digestive phases as well as $\mathrm{V}$ for the gastric phase. Ni only shows limited correlations between pseudo-total sample concentrations and respective bioaccessible concentrations for both phases. Figure 8 furthermore shows that bioaccessible As and $\mathrm{Cd}$ concentrations follow a well-defined general trend across the measured pseudo-total concentration ranges for As and $\mathrm{Cd}$. With regard to the relationship between pseudo-total and respective bioaccessible concentrations for the remaining PTEs considered in this study, Figure 8 also highlights that for individual samples, the measured bioaccessible concentrations do not follow the bioaccessibility fraction as portrayed 
in the overall general trend. This can be observed for $\mathrm{Co}, \mathrm{Cu}$ and $\mathrm{Cr}$ with individual samples showing a higher bioaccessibility fraction. $\mathrm{Pb}$ and $\mathrm{Cu}$ concentrations furthermore also exhibit individual samples with a lower bioaccessibility fraction than the respective overall general trend. The plots for $\mathrm{Ni}$ and $\mathrm{V}$ as well as to a lesser degree for $\mathrm{Cr}$ and $\mathrm{U}$ show some distinct features across the measured pseudo-total and bioaccessible concentration range which may reflect the presence of two distinct bioaccessibility fractions across the sample subset. A crosselement correlation study shows strong positive correlations (Pearson Correlation Coefficient $\mathrm{r}>0.7$ ) between the gastric-phase bioaccessible concentrations of $\mathrm{Cd}$ and pseudo-total concentrations of $\mathrm{Zn}(\mathrm{r}=0.9842)$. Similar strong correlations are observed between bioaccessible $\mathrm{Cr}$ and pseudo-total concentrations of Co (r=0.7296), Ni (r=0.7638) and V $(\mathrm{r}=0.796)$. Furthermore, bioaccessible $\mathrm{Pb}$ was strongly correlated with pseudo-total concentrations of $\mathrm{Zn}(\mathrm{r}=0.767)$ and $\mathrm{Cd}(\mathrm{r}=0.765)$ as well as between bioaccessible $\mathrm{Zn}$ and pseudo-total Cd concentrations ( $\mathrm{r}=0.989)$.

This concurs with the spatial distribution of elevated concentrations of these PTEs and suggests distinct bioacessibility fractions may be associated with different lithological controls. The calculated bioaccessible fraction (BAF) for individual PTEs and their respective bioaccessible concentrations for the gastric phase have been mapped to investigate any apparent relationship with lithological controls (Figs. 9-11). The association between the spatial distribution of elevated PTE concentrations of Ni, Cr, Co, V and Cu and the Antrim Lava Group (Figs. 6 and 7) is observed for the calculated BAF but not replicated in all cases for the gastric phase. Chromium is the notable anomaly where bioaccessible concentrations of up to $9.96 \mathrm{mg} / \mathrm{kg}$ are recorded for the gastric phase in the basaltic lavas. High calculated BAFs and gastric phase concentrations for $\mathrm{As}, \mathrm{Cd}, \mathrm{Co}$ and $\mathrm{Ni}$ (along with high $\mathrm{Pb}, \mathrm{Zn}$ anomalies) show a close association with sandstones and shales of the Southern Upland Terrain and with Palaeozoic intrusives (Slieve Gullion and Newry granodiorites).

\section{Discussion}

When comparing the pseudo-total PTE concentrations (by ICP-MS/OES) from the Tellus survey and the study sample subset with the results obtained by similar analytical techniques as 
part of previous soil geochemical surveys completed in Northern Ireland the specific sampling regime of the individual surveys needs to be considered. While soil samples retrieved as part of the Tellus Survey and as part of the previous surveys documented by Jordan et al. (2000) were collected from a depth interval of 5-20 $\mathrm{cm}$ and $5-25 \mathrm{~cm}$ below ground surface, respectively, samples collected as part of the UK Soil and Herbage Pollutant Survey/UKSHPS (Barraclough, 2007) were retrieved from much shallower depth of up to $5 \mathrm{~cm}$ below ground surface. Table 2 shows that for a number of PTEs, including $\mathrm{As}, \mathrm{Cd}$ and $\mathrm{Cu}$, the observed concentrations ranges are however similar across the different datasets. For $\mathrm{Co}$ and $\mathrm{Cr}$, the concentrations observed in the Tellus survey are lower than those observed in the previous survey summarized by Jordan et al. (2000). At the same time, the concentrations for Pb observed in the Tellus data commonly exceed the concentrations reported by Jordan et al. (2000). Pseudo-total concentrations of Ni and $\mathrm{Zn}$ are similar between the Tellus Survey and the previous survey reported by Jordan et al. (2000). With regard to the more shallow samples analysed as part of the UKSHPS, Cr and Zn concentrations observed in the more shallow UKSHPS samples exceed the concentrations observed in the Tellus Survey. Lead and Ni concentrations in the Tellus samples however exceeded the concentrations observed in the shallow UKSHPS samples.

Figure 5 and Table 4 illustrate the strong correlations between specific element abundances such as Ni-Cr, Ni-Co, Cr-V-Co, Ni-V and Cr-Co. The natural occurrence of these elements has been associated with (ultra-)mafic rocks and igneous ore deposits (Lewis, 1993; Swaine, 1960; Jordan et al., 2000). This lithological correlation concurs with the geostatistical analysis, highlighting the strong control of the Antrim Lava Group on the spatial distribution of the above PTEs.

As observed in Figure 5, exceedences of the respective SGV/GAC values for $\mathrm{As}, \mathrm{Ni}, \mathrm{Cu}, \mathrm{Pb}$, $\mathrm{Zn}$ and $\mathrm{Cd}$ were observed for a number of outlier values within the Tellus data set and the study sample sub-set. Moreover, a large number of samples exceeded the respective SGV/GAC value for $\mathrm{Cr}$ and $\mathrm{V}$. The geostatistical analysis showed the association of elevated PTE concentrations in excess of respective SGV/GAC values, for example for Ni, with the Antrim Lava Group, as previously observed by Zhang et al. (2008). Variations of Ni concentrations across the Upper and Lower Basalts of the Antrim Lava Group are likely to be related to the 
role of olivine fractionation in the differentiation of the Basalt formations as described by Lyle (1979) and Lyle and Patton (1989). Variability of V concentrations (as $\mathrm{V}_{2} \mathrm{O}_{3}$ ) where observed by Patterson and Mitchell (1955) for the Basalt succession of the Antrim Lava Group.

The UBM tests highlighted that significant fractions of individual PTE concentrations where bioaccessible for the gastric and the gastrio-intestinal phase, respectively. In general, bioaccessible concentrations were higher for the gastric phase extractions, as may be predicted in view of the applied $\mathrm{pH}$ regime (Baes and Mesmer, 1986) and as similarly observed by Poggio et al. (2009) and Gbefa et al. (2011) when investigating contaminated land scenarios. Comparing the calculated bioaccessible fractions (BAF\%) for individual PTEs of the study subset (Table 6) with other studies such as Madrid et al. (2008), Okorie et al. (2011) and Poggio et al. (2009) investigating human bioaccessibility of anthropogenic soil pollution showed that in the presented study lower BAF\% values were generally observed for $\mathrm{Cr}$ and $\mathrm{Ni}$ as well as for $\mathrm{As}, \mathrm{Zn}$ and $\mathrm{Cu}$. This general difference in lower bioaccessibility values for naturally occurring/geogenous PTEs versus PTEs associated with anthropogenic sources has been generally reported (Ljung et al., 2007).

While Nathanail et al. (2009) report that the relationship between pseudo-total concentrations and the respective bioaccessible fraction is not necessarily linear, Table 7 and Figure 8 show that a number of strong correlations between individual pseudo-total PTE concentration and respective bioaccessible concentrations (gastric phase) are observed in the study data set. Figure 8 illustrates that for some PTEs, such as $\mathrm{As}, \mathrm{Cd}, \mathrm{Co}, \mathrm{Cu}$ and $\mathrm{Pb}$ this relationships follows a general linear trend. In doing so, a number of outliers can be observed with an either 'anomalously' high or low bioaccessibility fraction for some of these PTEs ( $\mathrm{Co}, \mathrm{Cu}$ and $\mathrm{Pb}$ ). Outliers are often observed to be associated with igneous (basalt) soil parent material (Co and $\mathrm{Cu}$ ). With regard to $\mathrm{Cu}$, both 'anomalously' high as well as low bioaccessibility fractions are associated with individual soil samples derived from 'basalt' soil parent material. Previous studies by Lyle (1979), Lyle and Patton (1989) and Patterson and Mitchell (1995) demonstrate the geochemical variability of the basalt parent material of the Antrim Lava Group. 
The cross-element correlation study showed strong positive correlations between gastric-phase bioaccessible concentrations of $\mathrm{Cd}$ and pseudo-total concentrations of $\mathrm{Zn}$, bioaccessible $\mathrm{Cr}$ and pseudo-total concentrations of $\mathrm{Co}, \mathrm{Ni}$, and $\mathrm{V}$ as well as between bioaccessible $\mathrm{Pb}$ with pseudototal concentrations of $\mathrm{Zn}$ and $\mathrm{Cd}$ and between bioaccessible $\mathrm{Zn}$ and pseudo-total $\mathrm{Cd}$ concentrations. While these correlations may reflect element interaction processes during the extraction stage as previously reported for $\mathrm{Pb}$ and $\mathrm{Zn}$ interactions (Finzgar et al., 2007) it is also plausible that these positive correlations represent an artefact of the original co-abundance of these elements associated with the soil parent material, as most of these elements are commonly associated with (ultra)mafic rocks and ore deposits.

With regard to $\mathrm{Cr}, \mathrm{Ni}, \mathrm{U}$ and $\mathrm{V}$, Figure 8 may be interpreted to reflect a combination of overlapping multiple relationships within the overall data sets for individual PTEs. This may reflect the varying relative abundance of different PTE species with specific bioaccessibility fractions as documented for example by Stewart et al. (2003) for Cr-III/Cr-VI bioaccessibilities. This varying relative preferential abundance of specific PTE species may in turn be related to individual soil parent materials and associated geochemical characteristics across Northern Ireland.

Figure 4 illustrates the widespread exceeded values of the GAC for $\mathrm{Cr}$ and V (Table 3). Exceedences of the $\mathrm{Cr}$ GAC are largely based on the conservative assumption that observed $\mathrm{Cr}$ concentrations are present as $\mathrm{Cr}-\mathrm{VI}$ and thus require site specific confirmation as part of a detailed quantitative risk assessment approach. Exceedence of the Vanadium GAC is also widely observed. For both, the UBM bioaccessibility testing however yielded relatively low BAF values of $7.77 \%$ median BAF-V and $1.12 \%$ median BAF-Cr when compared to a median BAF-Cr values of $22.9 \%$ for urban soils as observed by Okorie et al. (2011).

With regard to gastric BAFs for individual PTEs as observed across key geological units as soil parent material, the study shows that BAFs generally fall below $10 \%$ for $\mathrm{Cr}$ and below $20 \%$ for $\mathrm{V}$ across the various key geological units. The BAFs for $\mathrm{U}$ generally ranges between 10-20\% across the individual units with the largest interquartile ranges observed for the Ballyshannon Limestone Formation and the Slieve Gullion Complex. Figure 7 illustrates the gastric BAFs for 
a number of individual PTEs showing marked variations across key geological units of soil parent material. With regard to As, Figure 12 shows that generally the As-BAF falls below $20 \%$ with a higher interquartile range observed for the metasediments of the Gala Group. The highest BAFs for Cd are observed for the metasediments, such as those from the Gala and Hawick Group as well as the Ballyshannon Limestone Formation (Fig. 12). Ni-BAFs show a higher median for the Upper Basalts of the Antrim Lava Formation than for the Lower Basalt of the formation. At the same time Ni-BAFs in the Upper Basalts are more positively skewed with a larger interquartile range. Generally, Ni-BAFs for both the Upper and Lower Basalts fall below 20\%. Highest median Ni-BAFs are observed for the Gala Group and the Lough Neagh Clays. With regard to $\mathrm{Pb}-\mathrm{BAFs}$, the median values for both the Upper and Lower Basalts are similar, although the interquartile range for the Upper Basalts is significantly larger. The highest $\mathrm{Pb}$-BAFs are again found in the metasediments (Gala Group and Hawick Group) as well as the Ballyshannon Limestone and the Clougher Valley Formations. Zn-BAFs generally show values below $20 \%$ across the units, with the largest interquartile ranges observed for the Upper Basalts, the Ballyshannon Limestone Formation and the Lough Neagh Clays. The distribution of BAFs for individual PTEs highlights that while some key soil parent materials, such as the Basalt succession of the Antrim Lava Group are associated with elevated pseudototal PTE concentrations in excess of current SGV/GAC values, with regard to the bioaccessibility of these individual PTEs, other units with moderate pseudo-total concentrations, such as the Gala Group exhibit far larger BAFs. This is furthermore demonstrated for the case of $\mathrm{Ni}$ in Figure 12, where the trend of lower bioaccessibility fractions (with values of bioaccessible $\mathrm{Ni}$ of below $10 \mathrm{mg} \mathrm{kg}^{-1}$ ) is predominantly provided by samples from basalt soil parent material, while the steeper trend of higher bioaccessibility fractions (with values of bioaccessible Ni of up to $>30 \mathrm{mg} \mathrm{kg}^{-1}$ ) is provided by samples from soil parent material associated with the Gala Group, Ballyshannon Limestone Formation and the Lough Neagh Clays. To this end, the study highlights that human health risk assessments for regions characterised by specific soil parent materials need to reflect the variability of observed PTE bioaccessibilities. 


\section{Conclusion}

Based on the comprehensive soil sampling and analysis programme completed by the Tellus Project (Smyth, 2007), the study investigated the abundance and spatial variability of observed geogenous pseudo-total concentrations of a range of PTEs in the context of their association with specific soil parent materials. In particular, the study supplemented the available Tellus soil geochemical database with additional oral bioacessibility data for a range of PTEs applying the widely acknowledged UBM procedure (BARGE-INERIS, 2011).

The analysis of pseudo-total PTE concentrations highlighted exceedence of respective GAC values for $\mathrm{V}$ and $\mathrm{Cr}$ (applying the $\mathrm{Cr}-\mathrm{VI}$ GAC value in a conservative approach) across Northern Ireland with further exceedence of respective $\mathrm{SGV} / \mathrm{GAC}$ values for $\mathrm{Cd}, \mathrm{Cu}, \mathrm{Ni}, \mathrm{Pb}$, and Zn. The UBM tests however showed in this context that for some soil parent materials which were associated with observed elevated pseudo-total PTE concentrations, the measured oral bioaccessible fraction was relatively low (e.g. Antrim Lava Group and Ni concentrations). On the other hand, for other soil parent materials with relatively moderate pseudo-total PTE concentrations, the measured oral bioaccessible fraction was relatively high (e.g. Gala Group). This in turn is likely to affect the outcomes of regional human health risk assessments for specific PTEs. The observed variations in oral BAF are likely to be related to the abundance of specific PTE species across the different soil parent materials which may have also been indicated by the differences in pseudo-total concentrations of individual PTEs as analysed by ICP-MS/OES or XRF.

The cross-element correlation study showed strong positive correlations between gastric-phase bioaccessible concentrations of specific PTEs and pseudo-total concentrations of other coelements. While some of these correlations may reflect element interactions during the extraction stage (e.g. $\mathrm{Pb}$ and $\mathrm{Zn}$ interactions) these correlations may also be rather associated with observed source co-abundances of specific PTEs for specific soil parent materials. A more detailed study focusing on individual element speciation and labiality together with bioaccessibility testing may provide further insight into element interactions affecting specific oral PTE bioaccessibilities. 
In comparing the findings of this study with previous regional soil geochemical studies, similarities were observed with studies employing similar sampling strategies, in particular depth selection (Jordan et al., 2000). The comparison with previous studies targeting more shallow sampling depths (Barraclough, 2007) showed partial similarities as well as marked differences (e.g. $\mathrm{Cr}, \mathrm{Zn} . \mathrm{Pb}, \mathrm{Ni})$. The variation of specific PTE concentrations across the vertical soil profile, its association with soil forming/weathering processes and soil conditions and in turn the associated implications on individual PTE speciation and PTE bioaccessibility was beyond the scope of this paper but presents an exciting challenge for future studies. Furthermore, the impact of Quaternary processes affecting the spatial distribution of soil parent material has not been explicitly investigated as part of this study but may further aid the more detailed spatial correlation of soil PTE concentrations and soil parent material in future studies.

The UBM bioaccessibility test has only been validated against in-vivo data for $\mathrm{As} \mathrm{Cd}$ and $\mathrm{Pb}$, whilst this shows is that it is a good analogue of bioavailability for these elements, the data for other elements can only be considered as a useful line of evidence in interpreting results. The test produces two results: the first mimicking the conditions found in the stomach in a fasting state ( $\mathrm{pH} 1.2)$; and the second mimicking the upper intestine with a higher $\mathrm{pH}$ (6.5). The higher $\mathrm{pH}$ of the latter stage can often lead to precipitation of elements giving rise to poorer reproducibility than the stomach phase extract (Wragg et al 2011). This should be taken into account when making interpretations using these data.

\section{Acknowledgements}

This research was funded by BGS University Funding Initiative (BUFI). Thanks to Maura Pringle for assistance with the preparation of figures. We are grateful for the valuable comments of our two anonymous reviewers. 
References

Alloway BJ. Bioavailability of Elements in Soil. In: Selinus O, Alloway BJ, Centeno JA, Finkelman RB, Fuge R, Lindh U, et al, editors. Essentials of Medical Geology. Amsterdam: Elsevier Academic Press; 2005.

Baes CF, Mesmer CE. The Hydrolysis of Cations Malabar, FL: Krieger Publishing; 1986.

BARGE - INERIS. UBM Procedure for the Measurement of Inorganic Contaminant Bioaccessibility from Solid Matrices 2011.

Barraclough D. UK Soil \& Herbage Pollutant Survey - Report 1: Introduction \& Summary 2007;SCHO0307BMEP-E-P.

Bonnard R, Bour O. Comparison of Lead Concentration in Surface Soil by Inducted Coupled Plasma/optical Emission Spectrometry and X-Ray Fluorescence. Helmholtz Centre Environmental Research-Ufz: Leipzig, Germany 2008; D-04318..

Broadway A, Cave MR, Wragg J, Fordyce FM, Bewley RJF, Graham MC et al. Determination of the bioaccessibility of chromium in Glasgow soil and the implications for human health risk assessment. Sci Total Environ 2010;409:267-77.

Cave MR, Wragg J, Denys S, Jondreville C, Feidt C. Oral Bioavailability. In: Swartjes FA, editor. Dealing with Contaminated Sites: Springer Netherlands; 2011. p. 287-324.

Davies BE, Bowman C, Davies TC, Selenius O. Medical Geology: Perspectives and Prospects. In: Selinus O, Alloway BJ, Centeno JA, Finkelman RB, Fuge R, Lindh U, et al, editors. Essentials of Medical Geology. Amsterdam: Elsevier Academic Press; 2005.

Deutsch CV, Journel AG. GSLIB: Geostatistical Software Library and User's Guide, Second Edition, New York: Oxford University Press; 1998.

Finzgar N, Tlustos P, Lestan D. Relationship of soil properties to fractionation, bioavailability and mobility of lead and zinc in soil. Plant Soil Environ 2007;53:225-38.

Gbefa BK, Entwistle JA, Dean JR. Oral bioaccessibility of metals in an urban catchment, Newcastle upon Tyne. Environ Geochem Health 2011;33:167-81.

Gringarten E, Deutsch CV. Teacher's Aide Variogram Interpretation and Modeling. Math Geol 2001;33:4:507-534. 
Gupta S, Vollmer M, Krebs R. The importance of mobile, mobilisable and pseudo total heavy metal fractions in soil for three-level risk assessment and risk management. Sci Total Environ 1996;178:11-20.

Hursthouse A. The relevance of speciation in the remediation of soils and sediments contaminated by metallic elements - an overview and examples from Central Scotland, UK RID A-9005-2010. J Environ Monit 2001;3:49-60.

Jeffries J, Martin I. Updated Technical Background to the CLEA Model 2009;SCHO0508BNQW-E-P.

Jensen JL, Corbett PWM, Pickup GE, Ringrose PS. Permeability variograms, geological structure, and flow performance: Math Geol. 1996;28:419-435.

Johnson CC, Breward N. G-Base: Geochemical Baseline Survey of the Environment 2004;CR/04/016N.

Jordan C, Higgins A, Hamill K, Cruickshank JG. The Soil Geochemical Atlas of Northern Ireland 2000.

Jordan C, Zhang C, Higgins A. Using GIS and statistics to study influences of geology on probability features of surface soil geochemistry in Northern Ireland. J Geochem Explor 2007;93:135-52.

Journal AG, Huijbregts CJ. Mining Geostatistics. Orlando: Academic Press; 1978.

Lado LR, Hengl T, Reuter HI. Heavy metals in European soils: A geostatistical analysis of the FOREGS Geochemical database RID F-7147-2010. Geoderma 2008;148:189-99.

Latawiec AE, Simmons P, Reid BJ. Decision-makers' perspectives on the use of bioaccessibility for risk-based regulation of contaminated land. Environ Int 2010;36:383-9.

Lewis Jr. RJ. Hawley's Condensed Chemical Dictionary New York: Van Nostrand Reinhold Co.; 1993.

Ljung K, Oomen A, Duits M, Selinus O, Berglund M. Bioaccessibility of metals in urban playground soils RID E-8958-2010. J Environ Sci Health Part A-Toxic/Hazard Subst Environ Eng 2007;42:1241-50.

Lloyd CD. Local Models for Spatial Analysis. CRC press:Taylor and Francis Group; London. 2007.

Lyle P. A Petrological and Geochemical Study of the Tertiary Basaltic Rocks of Northeast Ireland. J Earth Sci 1979;2:137-52. 
Lyle P, Patton DJS. The Petrography and Geochemistry of the Upper Basalt Formation of the Antrim Lava Group. Irish J Earth Sci 1989;10:33-41.

Madrid F, Biasioli M, Ajmone-Marsan F. Availability and bioaccessibility of metals in fine particles of some urban soils. Arch Environ Contam Toxicol 2008;55:21-32.

Marcos DR, Parsons J, Garcia H, Corral A, Cruz JG, Campos TA et al. Comparison of ICPOES and XRF Performance for Pb and As Analysis in environmental Soil Samples from Chihuahua, Mexico. Phys Rev \& Res Int 2011;1:29-44.

Martin I, Morgan H, Jones C, Waterfall E, Jeffries J. Soil Guideline Value for nickel in soil 2009a.

Martin I, Morgan H, Waterfall E. Soil Guideline Value for cadmium in soil 2009b.

Matheron G. Les variables régionalisées et leur estimation. Masson: Paris.1965.

McBratney AB, Webster R. Choosing functions for semivariograms of soil properties and fitting them to sample estimates. J Soil Sci 1986;37:617-639.

McBratney AB, Webster R, McClaren RG, Spiers RB. Regional Variation of extractable copper and cobalt in the topsoil of south-east Scotland. Agronomie 1982;2:969-82.

McKinley JM, Lloyd C D, Ruffell AH.Use of variography in permeability characterisation of visually homogeneous sandstone reservoirs with examples from outcrop studies. Math Geol 2004;36:7:761-779.

Meunier L, Walker SR, Wragg J, Parsons MB, Koch I, Jamieson HE et al. Effects of Soil Composition and Mineralogy on the Bioaccessibility of Arsenic from Tailings and Soil in Gold Mine Districts of Nova Scotia. Environ Sci Technol 2010;44:2667-74.

Mitchell W.I. The Geology of Northern Ireland - Our natural Foundation. GSNI Belfast; 2004.

Morillo E, Romero AS, Maqueda C, Madrid L, Ajmone-Marsan F, Grcman H et al. Soil pollution by PAHs in urban soils: a comparison of three European cities RID A-9005-2010. J Environ Monit 2007;9:1001-8.

Nathanial P, McCaffrey C, Ashmore M, Cheng Y, Gillet A, Ogden R et al. The LQM/CIEH Generic Assessment Criteria for Human Health Risk Assessment (2nd Edition) 2009.

Nordberg M, Cherian MG. Biological Responses of Elements. In: Selinus O, Alloway BJ, Centeno JA, Finkelman RB, Fuge R, Lindh U, et al, editors. Essentials of Medical Geology. Amsterdam: Elsevevier Academic Press; 2005. 
Okorie A, Entwistle J, Dean JR. The application of in vitro gastrointestinal extraction to assess oral bioaccessibility of potentially toxic elements from an urban recreational site. Appl Geochem 2011;26:789-96.

Patterson EM, Mitchell WA. The Tertiary Lava Succession in the Northern Part of the Antrim Plateau. Proceedings of the RIA. Section B: Biological, Geological and Chemical Science 1955;57:79-122.

Pebesma EJ, Wesseling CG. Gstat, a program for geostatistical modelling, prediction and simulation: Com and Geosci 1998;24:17-31.

Poggio L, Vrscaj B, Schulin R, Hepperle E, Marsan FA. Metals pollution and human bioaccessibility of topsoils in Grugliasco (Italy). Environ Pollut 2009;157:680-9.

Pyle S, Nocerino J, Deming S, Palasota J, Palasota J, Miller E et al. Comparison of AAS, ICPAES, PSA, and XRF in determining lead and cadmium in soil. Environ Sci Technol 1996;30:204-13.

Reimann C, Filzmoser P. Normal and lognormal data distribution in geochemistry: death of a myth. Consequences for the statistical treatment of geochemical and environmental data.

Environ Geol 2000;39:1001-14.

Rothstein H, Irving P, Walden T, Yearsley R. The risks of risk-based regulation: Insights from the environmental policy domain. Environ Int 2006;32:8:1056-1065.

Ruby M. Bioavailability of soil-borne chemicals: Abiotic assessment tools. Hum Ecol Risk Assess 2004;10:647-56.

Ruby M, Davis A, Schoof R, Eberle S, Sellstone C. Estimation of lead and arsenic bioavailability using a physiologically based extraction test. Environ Sci Technol 1996;30:42230 .

Scancar J, Milacic R, Horvat M. Comparison of various digestion and extraction procedures in analysis of heavy metals in sediments. Water Air Soil Pollut 2000;118:87-99.

Sialelli J, Davidson CM, Hursthouse AS, Ajmone-Marsan F. Human bioaccessibility of Cr, $\mathrm{Cu}$, $\mathrm{Ni}, \mathrm{Pb}$ and $\mathrm{Zn}$ in urban soils from the city of Torino, Italy. Environ Chem Lett 2011;9:197-202.

Smyth D. Methods used in the Tellus Geochemical Mapping of Northern Ireland 2007;OR/02/022.

Spijker J. Geochemical Patterns in the Soils of Zeland - Natural Variability versus Anthropogenic Impact 2005. 
Stewart M, Jardine P, Brandt C, Barnett M, Fendorf S, McKay L et al. Effects of contaminant concentration, aging, and soil properties on the bioaccessibility of $\mathrm{Cr}$ (III) and $\mathrm{Cr}$ (VI) in soil. Soil Sed Contam 2003;12:1-21.

Swaine DJ, Mitchell RL. Trace-Element Distribution in Soil Profiles. J Soil Sci 1960;11:34768.

Tipping E, Lawlor A, Lofts S, Shotbolt L. Simulating the long-term chemistry of an upland UK catchment: Heavy metals. Environ Pollut 2006;141:139-50.

Tukey JW. Exploratory Data Analysis. Reading, MA; Addison-Wesley: 1977.

Ure A. Single extraction schemes for soil analysis and related applications. Sci Total Environ 1996;178:3-10.

Van De Wiele, Tom R, Oomen AG, Wragg J, Cave M, Minekus M, Hack A. et al. Comparison of five in vitro digestion models to in vivo experimental results: Lead bioaccessibility in the human gastrointestinal tract. J Environ Sci Health Part A 2007;42:1203-11.

Wragg J. BGS Guidance Material 102, Ironstone Soil, Certificate of Analysis 2009;IR/09/006.

Wragg J, Cave M, Taylor H, Basta N, Brandon E, Casteel S et al. Interlaboratory Trial of a Unified Bioaccessibility Procedure 2009;OR/07/027.

Wragg J, Cave MR. In-vitro Methods for the Measurement of the Oral Bioaccessibility of Selected Metals and Metalloids in Soils: A Critical Review 2003;P5-062/TR/01.

Wragg J, Cave MR, Basta N, Brandon E, Casteel S, Denys SEB. et al. An Inter-laboratory Trial of the Unified BARGE Bioaccessibility Method for Arsenic, Cadmium and Lead in Soil. Sci Total Environ 2011; 409: 4016-4030.

Zhang C, Fay D, McGrath D, Grennan E, Carton OT. Statistical analyses of geochemical variables in soils of Ireland. Geoderma 2008;146:378-90. 


\section{TABLES}

Table 1 Potentially Toxic Elements (PTEs), method detection limits and analysis method

Table 2 Summary of individual PTE concentrations from Tellus dataset (Tellus) and Study subset (Study) as well as from previous studies.

Table 3 Environment Agency (EA) Soil Guideline Values (SGV) and Generic Assessment Criteria (GAC) as published by Land Quality Management (LQM) $\&$ Chartered Institute of Environmental Health (CIEH) for individual PTEs.

Table 4 Pearson Correlation Coefficient for individual combinations of PTE pseudototal concentrations (XRF).

Table 5 Parameters of the spherical models fitted to the experimental variograms for all PTEs except $\mathrm{U}$ which displayed no spatial structure; $\left(c_{0}\right)$ is the nugget variance, $(c)$ is the sill variance and $(a)$ is the range.

Table 6 Bioaccessible Fraction (BAF) for individual PTEs using pseudo-total PTE concentrations as per XRF analysis and respective bioaccessible PTE concentrations for gastric and gastro-intestinal digestive extracts from UBM test.

Table 7 Pearson Correlation Coefficient ( $\mathrm{r}$ ) for individual PTEs between pseudo-total concentrations (XRF) and respective bioaccessible concentrations in gastric and gastric-intestinal phase as per UBM test.

\section{FIGURES}

Figure 1 Geological map with locations of sampling locations. Geological map simplified from Mitchell 2004.

Figure 2 Normal Probability Plots for individual PTE pseudo-total concentrations $\mathrm{mgkg}^{-1}$

Figure 3 Comparative Boxplots of individual PTE pseudo-total concentrations as determined by XRF and ICP

Figure 4 Comparative Boxplots of Boxplots of individual PTE pseudo-total concentrations (by XRF) for the Tellus Database and the Study Sample subset

Figure 5 Cross-element Scatter Plots for specific pseudo-total PTE Concentrations (mgkg ${ }^{1}$ ) showing high correlation values

Figure 6 Kriged outputs maps demonstrating the spatial distribution of $\mathrm{As}, \mathrm{Cd}, \mathrm{Co}$ and $\mathrm{Cr}$ concentrations in $\mathrm{mgkg}^{-1}$. 
Figure $7 \quad$ Kriged outputs maps demonstrating the spatial distribution of $\mathrm{Ni}, \mathrm{Pb}, \mathrm{V}$ and $\mathrm{Zn}$ concentrations in $\mathrm{mgkg}^{-1}$.

Figure 8 Plots of individual pseudo-total PTE concentrations (by XRF) versus respective gastric bioaccessible PTE concentrations

Figure 9 Maps showing the spatial distribution of calculated bioaccessible fraction (BAF) for $\mathrm{As}, \mathrm{Cd}$ and $\mathrm{Co}$, and their respective bioaccessible concentrations for the gastric phase.

Figure 10 Maps showing the spatial distribution of calculated bioaccessible fraction (BAF) for $\mathrm{Cr}, \mathrm{Ni}$ and $\mathrm{Pb}$, and their respective bioaccessible concentrations for the gastric phase.

Figure 11 Maps showing the spatial distribution of calculated bioaccessible fraction (BAF) for $\mathrm{U}, \mathrm{V}$ and $\mathrm{Zn}$, and their respective bioaccessible concentrations for the gastric phase.

Figure 12 Comparative boxplots of individual PTE-BAFs mapped for specific soil parent materials 


\begin{tabular}{ccccc}
\hline \hline PTE & \multicolumn{2}{c}{ XRF } & \multicolumn{2}{c}{ ICP-MS/OES } \\
\hline \hline & MDL $\left[\mathrm{mgkg}^{-1}\right]$ & Method & $M D L\left[m g \mathrm{~kg}^{-1}\right]$ & Method \\
\cline { 2 - 5 } $\mathrm{As}$ & 0.9 & WD-XRF & 0.1 & ICP-MS \\
$\mathrm{Cd}$ & 0.5 & ED-XRF & 0.01 & ICP-MS \\
$\mathrm{Co}$ & 1.5 & WD-XRF & 0.1 & ICP-MS \\
$\mathrm{Cr}$ & 3.0 & WD-XRF & 1.0 & ICP- \\
$\mathrm{Cu}$ & 1.3 & WD-XRF & 0.5 & ICP- \\
$\mathrm{Ni}$ & 1.4 & WD-XRF & 0.5 & ICP-MS \\
$\mathrm{Pb}$ & 1.3 & WD-XRF & 0.2 & ICP-MS \\
$\mathrm{U}$ & 0.5 & WD-XRF & 0.05 & ICP-MS \\
$\mathrm{V}$ & 2.9 & WD-XRF & 1.0 & ICP- \\
$\mathrm{Zn}$ & 1.2 & WD-XRF & 1.0 & ICP- \\
\hline \hline $\mathrm{Tabl} 1$ & & & & OES \\
\hline
\end{tabular}

Table 1 


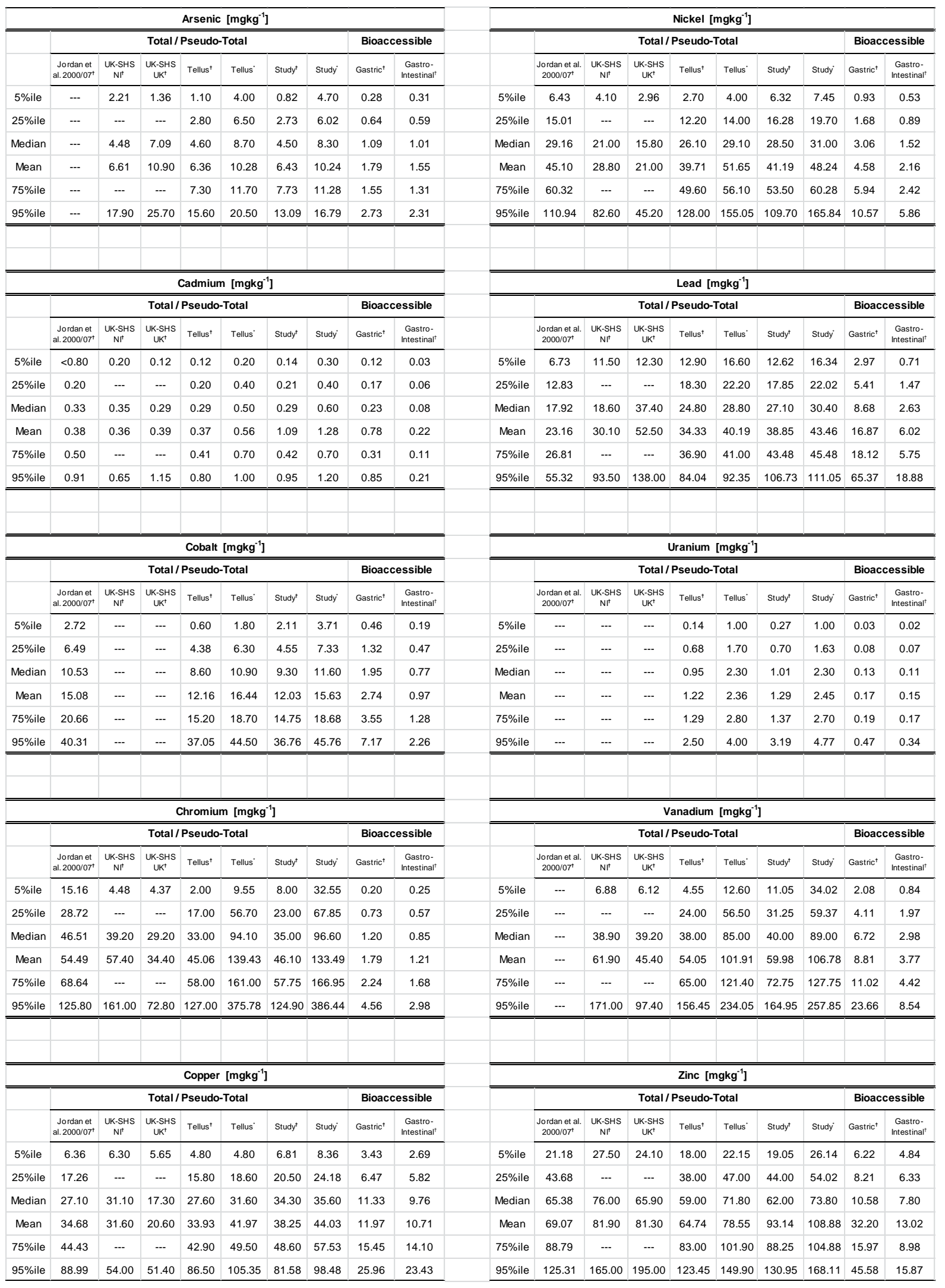

Table 2 


\begin{tabular}{ccccccccc}
\hline \hline & \multicolumn{2}{c}{ EA - SGV [mgkg } & -1 & DW] & \multicolumn{5}{c}{ LQM/CIEH - GAC [mgkg $^{-1}$ DW] } \\
\hline \hline PTE & As & Cd & $N i$ & $C r-I I I$ & $C r-V I$ & $C u$ & $V$ & $Z n$ \\
\hline Residential & 32 & 10.0 & 130 & 3000 & 4.3 & 2330 & 75 & 3750 \\
Allotment & 43 & 1.8 & 230 & 34600 & 2.1 & 524 & 18 & 618 \\
$\begin{array}{c}\text { Commercia } \\
\text { I }\end{array}$ & 640 & 230.0 & 1800 & 30400 & 35.0 & 71700 & 3160 & 665000 \\
\hline \hline Table 3 & & & & & & & &
\end{tabular}

\section{Correlation Coefficient}

\begin{tabular}{|c|c|c|c|c|c|c|c|c|c|c|}
\hline & As & Cd & Co & $\mathrm{Cr}$ & $\mathrm{Cu}$ & $\mathbf{N i}$ & $\mathrm{Pb}$ & V & $\mathbf{U}$ & $\mathrm{Zn}$ \\
\hline As & 1 & & & & & & & & & \\
\hline Cd & 0.0879 & 1 & & & & & & & & \\
\hline Co & -0.0788 & 0.1038 & 1 & & & & & & & \\
\hline $\mathrm{Cr}$ & -0.1227 & -0.0334 & 0.8936 & 1 & & & & & & \\
\hline $\mathrm{Cu}$ & -0.0369 & 0.1002 & 0.7147 & 0.6292 & 1 & & & & & \\
\hline $\mathrm{Ni}$ & -0.0800 & 0.0671 & 0.9395 & 0.9514 & 0.7278 & 1 & & & & \\
\hline $\mathrm{Pb}$ & 0.1745 & 0.6172 & -0.0363 & -0.0683 & 0.1458 & 0.0165 & 1 & & & \\
\hline $\mathbf{v}$ & -0.1038 & -0.0148 & 0.8931 & 0.8264 & 0.5850 & 0.8161 & -0.1078 & 1 & & \\
\hline $\mathbf{U}$ & 0.1016 & -0.0115 & -0.3125 & -0.3623 & -0.1072 & -0.3129 & 0.1195 & -0.2817 & 1 & \\
\hline $\mathrm{Zn}$ & 0.1114 & 0.9837 & 0.1876 & 0.0419 & 0.2105 & 0.1500 & 0.6602 & 0.0609 & -0.0132 & 1 \\
\hline
\end{tabular}

Table 4 


\begin{tabular}{|c|c|c|c|c|c|c|c|c|}
\hline \multirow[t]{2}{*}{ Element } & \multicolumn{8}{|c|}{ Modelled parameters } \\
\hline & $c_{0}$ & $c_{1}$ & $c 2$ & a1 & a2 & $\mathrm{C}_{0}+\mathrm{C}_{1}+\mathrm{C}_{2}$ & $c_{0}: c_{0}+c_{1}+c_{2}$ & $\%$ \\
\hline As & 64.17 & 19.40 & 14.17 & 7436 & 42311.9 & 83.56 & 0.7679 & 76.79 \\
\hline $\mathrm{Cd}$ & 0.42 & 0.17 & & 10000 & & 0.59 & 0.7124 & 71.24 \\
\hline Co & 54.61 & 152.78 & & 73603.7 & & 207.39 & 0.2633 & 26.33 \\
\hline $\mathrm{Cr}$ & 3773.63 & 1590.93 & 11760.50 & 10370.4 & 89597.6 & 17125.06 & 0.2204 & 22.04 \\
\hline $\mathrm{Cu}$ & 1001.33 & 690.74 & & 60425.1 & & 1692.07 & 0.5918 & 59.18 \\
\hline $\mathrm{Ni}$ & 741.33 & 1220.30 & 3284.49 & 50817.8 & 73913.7 & 5246.12 & 0.1413 & 14.13 \\
\hline $\mathrm{Pb}$ & 55056.60 & 12324.10 & & 17736 & & 67380.70 & 0.8171 & 81.71 \\
\hline V & 1250.32 & 3644.78 & & 81864.3 & & 4895.10 & 0.2554 & 25.54 \\
\hline $\mathrm{Zn}$ & 1521.50 & 2078.69 & & 95924.3 & & 3600.19 & 0.4226 & 42.26 \\
\hline
\end{tabular}

Table 5 


\begin{tabular}{|c|c|c|c|c|c|c|c|c|c|c|}
\hline \multicolumn{3}{|c|}{ As } & \multicolumn{2}{|c|}{ Cd } & \multicolumn{2}{|c|}{ Co } & \multicolumn{2}{|c|}{$\mathrm{Cr}$} & \multicolumn{2}{|c|}{$\mathrm{Cu}$} \\
\hline & \multicolumn{2}{|c|}{ BAF \% } & \multicolumn{2}{|c|}{ BAF $\%$} & \multicolumn{2}{|c|}{ BAF \% } & \multicolumn{2}{|c|}{ BAF \% } & \multicolumn{2}{|c|}{ BAF \% } \\
\hline & Gastric & $\begin{array}{c}\text { Gastro- } \\
\text { Intestinal }\end{array}$ & Gastric & $\begin{array}{c}\text { Gastro- } \\
\text { Intestinal }\end{array}$ & Gastric & $\begin{array}{c}\text { Gastro- } \\
\text { Intestinal }\end{array}$ & Gastric & $\begin{array}{c}\text { Gastro- } \\
\text { Intestinal }\end{array}$ & Gastric & $\begin{array}{r}\text { Gastro- } \\
\text { Intestina }\end{array}$ \\
\hline $5 \%$ ile & 5.23 & 5.86 & 25.85 & 6.19 & 7.81 & 3.03 & 0.58 & 0.45 & 12.09 & 11.05 \\
\hline $25 \%$ ile & 9.64 & 8.69 & 33.42 & 11.46 & 12.53 & 5.04 & 0.90 & 0.63 & 22.57 & 20.57 \\
\hline Median & 13.33 & 11.98 & 46.40 & 16.74 & 16.43 & 6.26 & 1.12 & 0.81 & 31.37 & 27.76 \\
\hline Mean & 13.98 & 12.56 & 48.63 & 17.10 & 18.38 & 6.60 & 1.33 & 0.98 & 31.11 & 28.70 \\
\hline $75 \%$ ile & 16.60 & 14.82 & 61.95 & 20.76 & 21.73 & 7.90 & 1.61 & 1.25 & 38.03 & 34.17 \\
\hline $95 \%$ ile & 24.44 & 22.63 & 75.97 & 29.15 & 38.39 & 10.70 & 2.70 & 1.84 & 50.85 & 58.55 \\
\hline \multicolumn{3}{|c|}{$\mathrm{Ni}$} & \multicolumn{2}{|c|}{$\mathrm{Pb}$} & \multicolumn{2}{|c|}{$\mathbf{U}$} & \multicolumn{2}{|c|}{$\mathrm{V}$} & \multicolumn{2}{|c|}{$\overline{Z n}$} \\
\hline & \multicolumn{2}{|c|}{ BAF \% } & \multicolumn{2}{|c|}{ BAF \% } & \multicolumn{2}{|c|}{ BAF \% } & \multicolumn{2}{|c|}{ BAF $\%$} & \multicolumn{2}{|c|}{ BAF $\%$} \\
\hline & Gastric & $\begin{array}{c}\text { Gastro- } \\
\text { Intestinal }\end{array}$ & Gastric & $\begin{array}{l}\text { Gastro- } \\
\text { Intestinal }\end{array}$ & Gastric & $\begin{array}{c}\text { Gastro- } \\
\text { Intestinal }\end{array}$ & Gastric & $\begin{array}{c}\text { Gastro- } \\
\text { Intestinal }\end{array}$ & Gastric & $\begin{array}{r}\text { Gastro- } \\
\text { Intestina }\end{array}$ \\
\hline $5 \%$ ile & 3.01 & 1.86 & 12.45 & 2.75 & 1.52 & 1.50 & 3.03 & 1.07 & 6.93 & 4.25 \\
\hline $25 \%$ ile & 5.58 & 3.31 & 22.95 & 6.10 & 4.36 & 3.67 & 5.12 & 2.07 & 11.09 & 7.09 \\
\hline Median & 8.16 & 4.79 & 31.92 & 9.66 & 6.09 & 5.20 & 7.77 & 3.55 & 17.13 & 12.23 \\
\hline Mean & 12.16 & 5.50 & 32.98 & 10.86 & 6.54 & 5.59 & 8.72 & 3.99 & 22.17 & 13.25 \\
\hline $75 \%$ ile & 16.28 & 7.29 & 41.22 & 14.88 & 8.19 & 7.45 & 10.54 & 5.58 & 23.08 & 16.20 \\
\hline 95\%ile & 35.05 & 10.97 & 60.17 & 22.86 & 11.93 & 10.53 & 19.63 & 9.13 & 68.49 & 29.57 \\
\hline
\end{tabular}

Table 6

\begin{tabular}{ccc}
\hline \hline PTE & \multicolumn{2}{c}{ Correlation Coefficient $(r)$} \\
& gastric & gastro-intestinal \\
\hline \hline As & 0.9756 & 0.9758 \\
Cd & 0.9996 & 0.9995 \\
Co & 0.7696 & 0.7842 \\
Cr & 0.8327 & 0.7203 \\
$\mathbf{C u}$ & 0.6092 & 0.6126 \\
$\mathrm{Ni}$ & 0.3875 & 0.5145 \\
$\mathrm{~Pb}$ & 0.9333 & 0.9155 \\
$\mathbf{U}$ & 0.8287 & 0.8148 \\
$\mathrm{~V}$ & 0.6884 & 0.4848 \\
$\mathrm{Zn}$ & 0.9897 & 0.9875 \\
\hline \hline
\end{tabular}

Table 7 


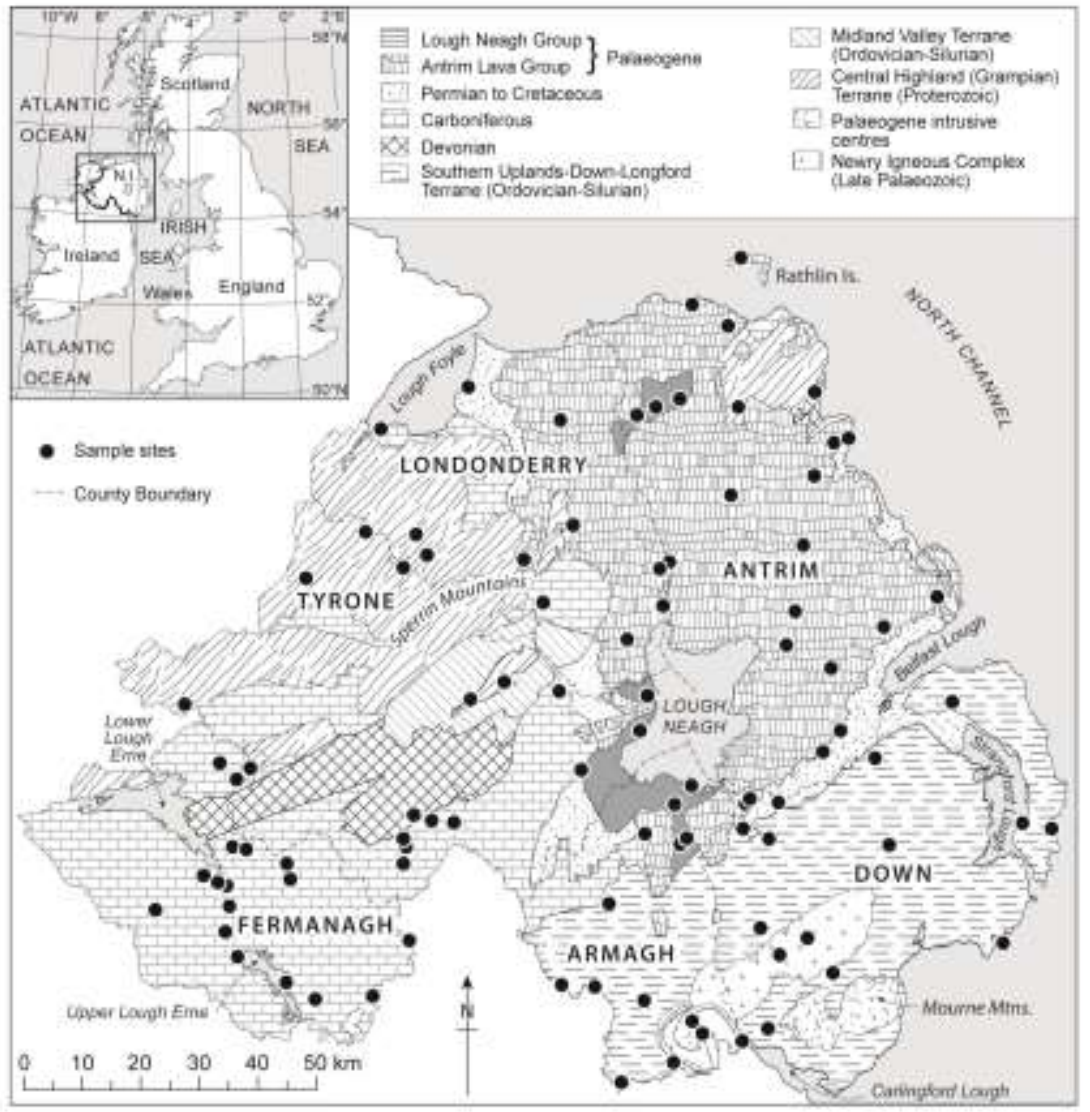

Figure 1 

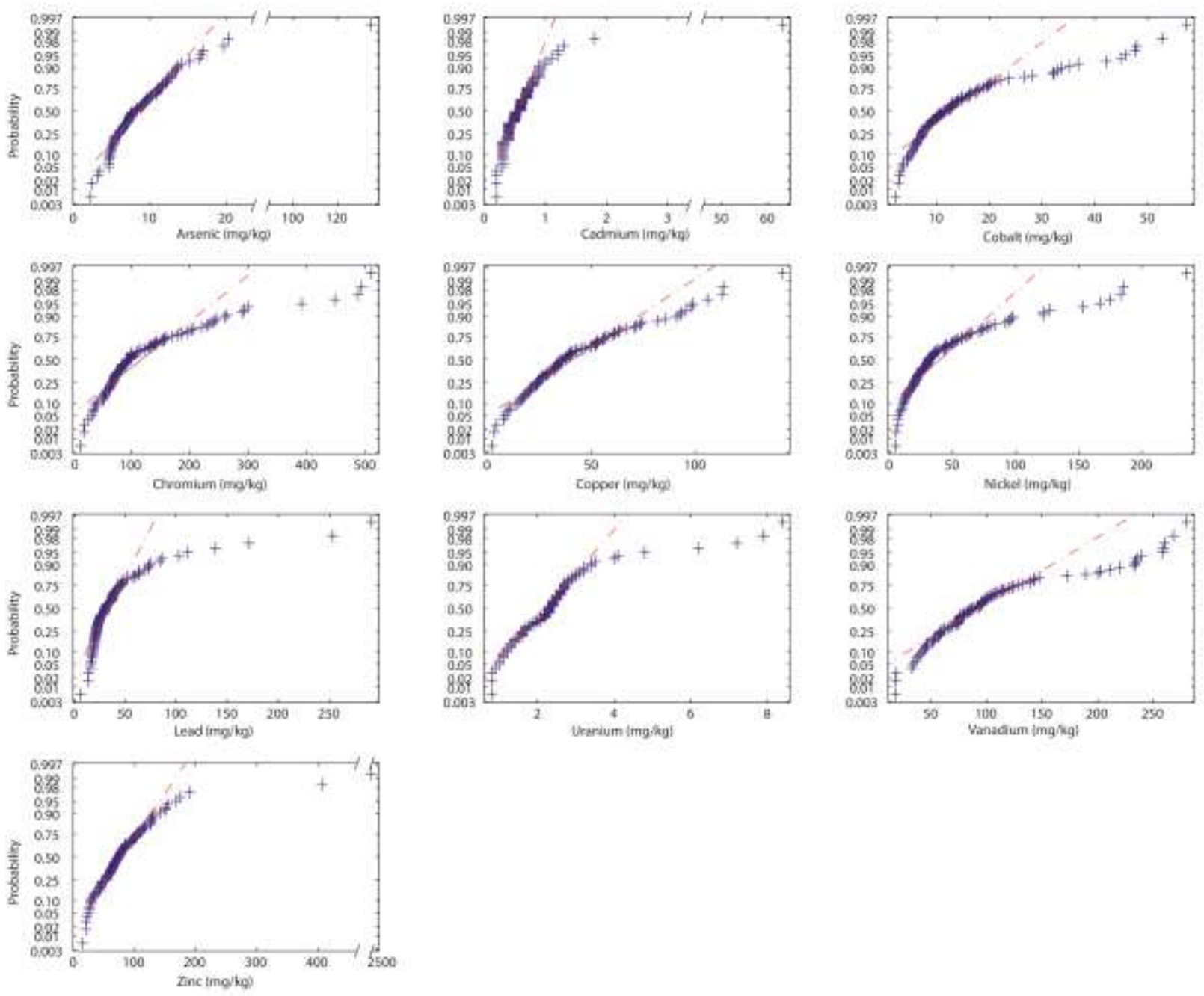

Figure 2 

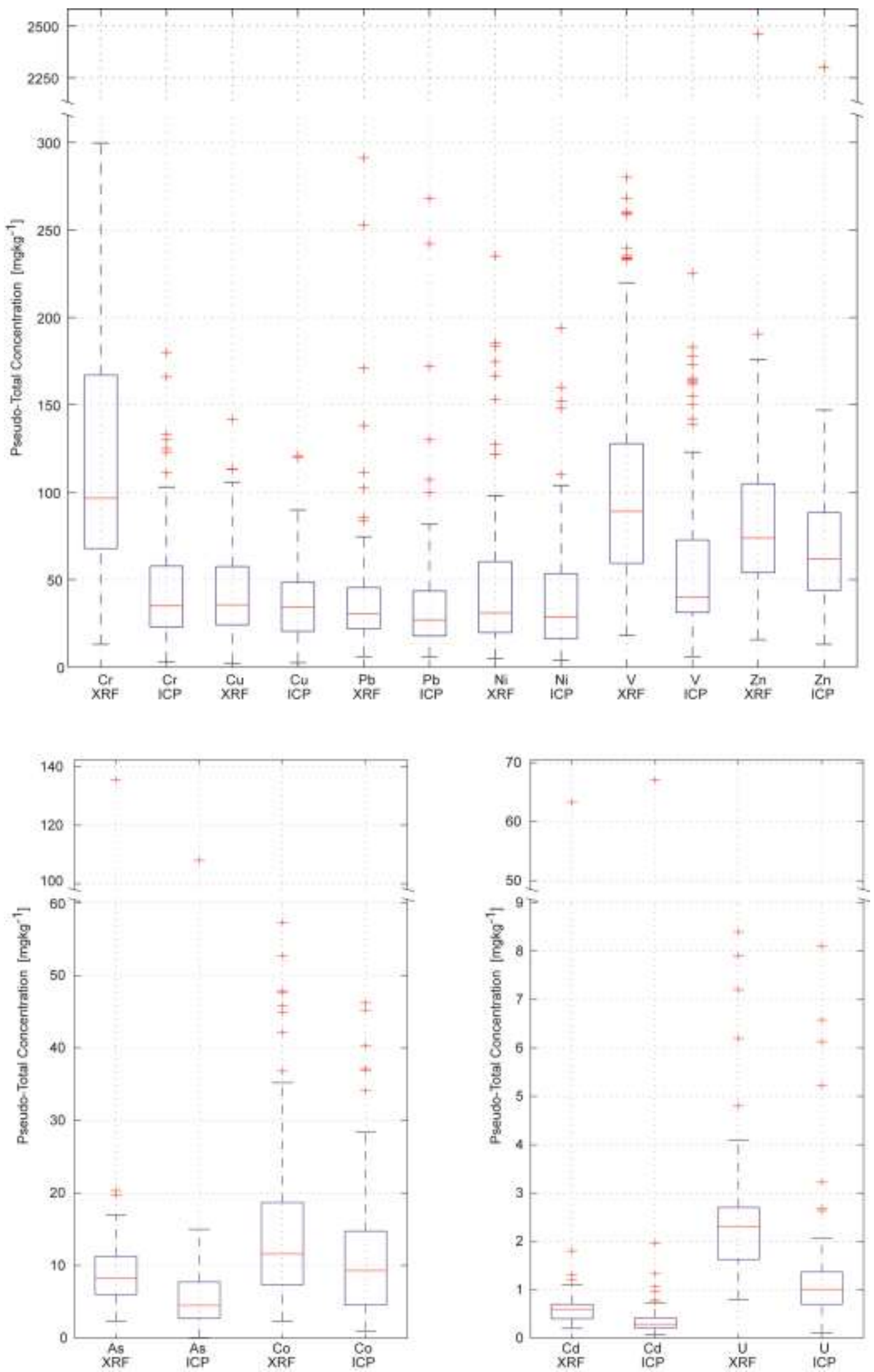

Figure 3 
Study Data Set ( $n=91$ )
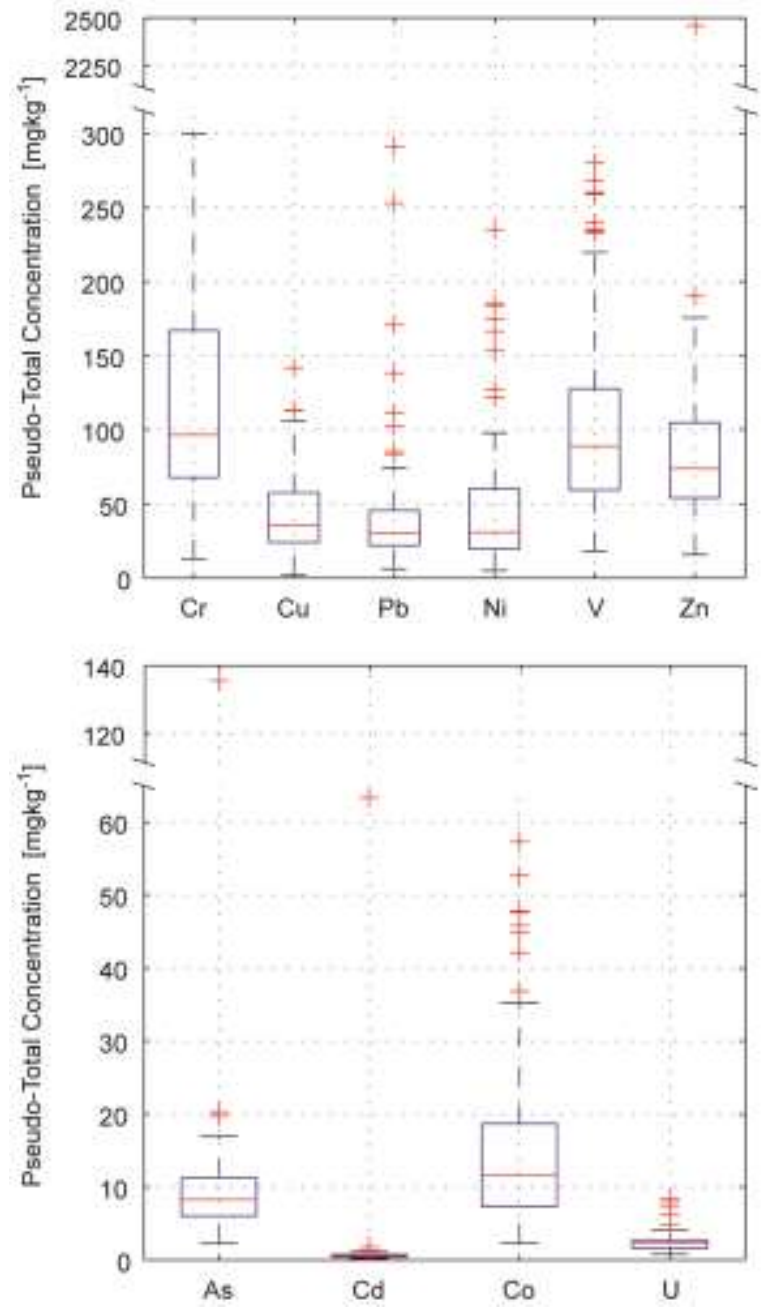

Tellus Data Set $(n=6861)$
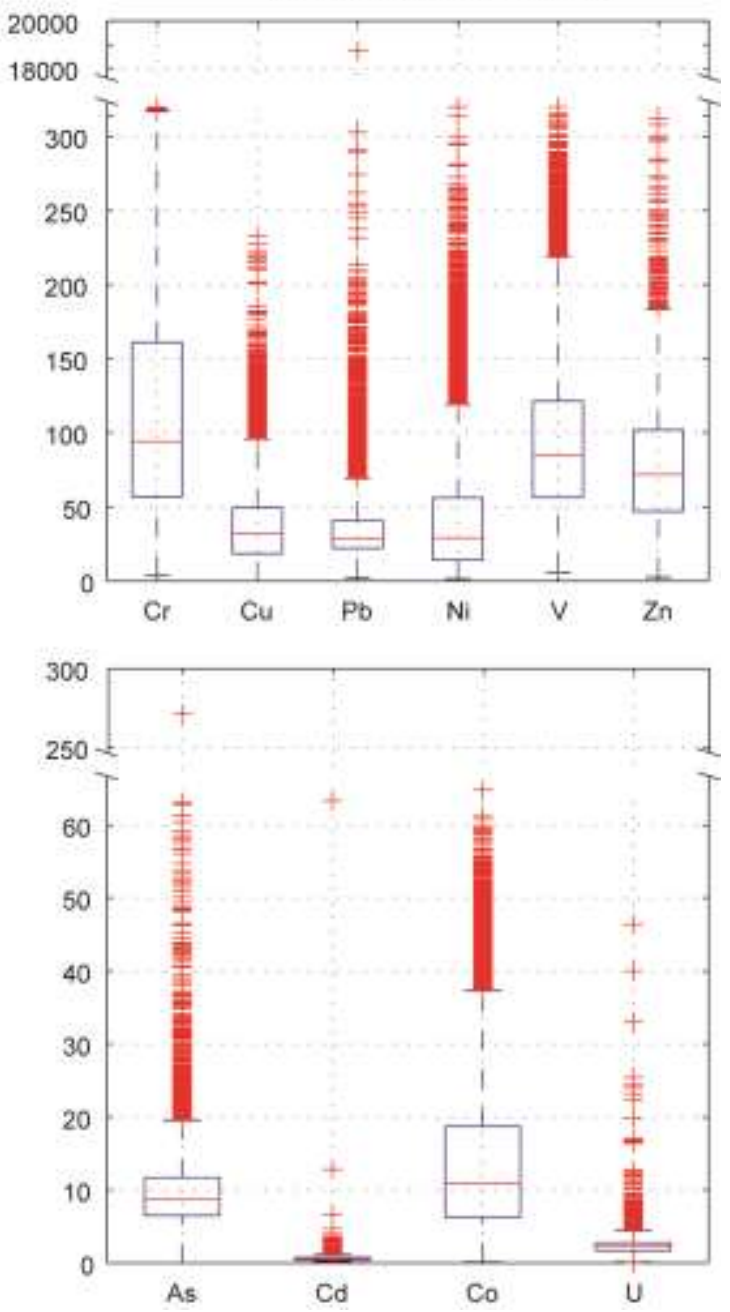

Figure 4 

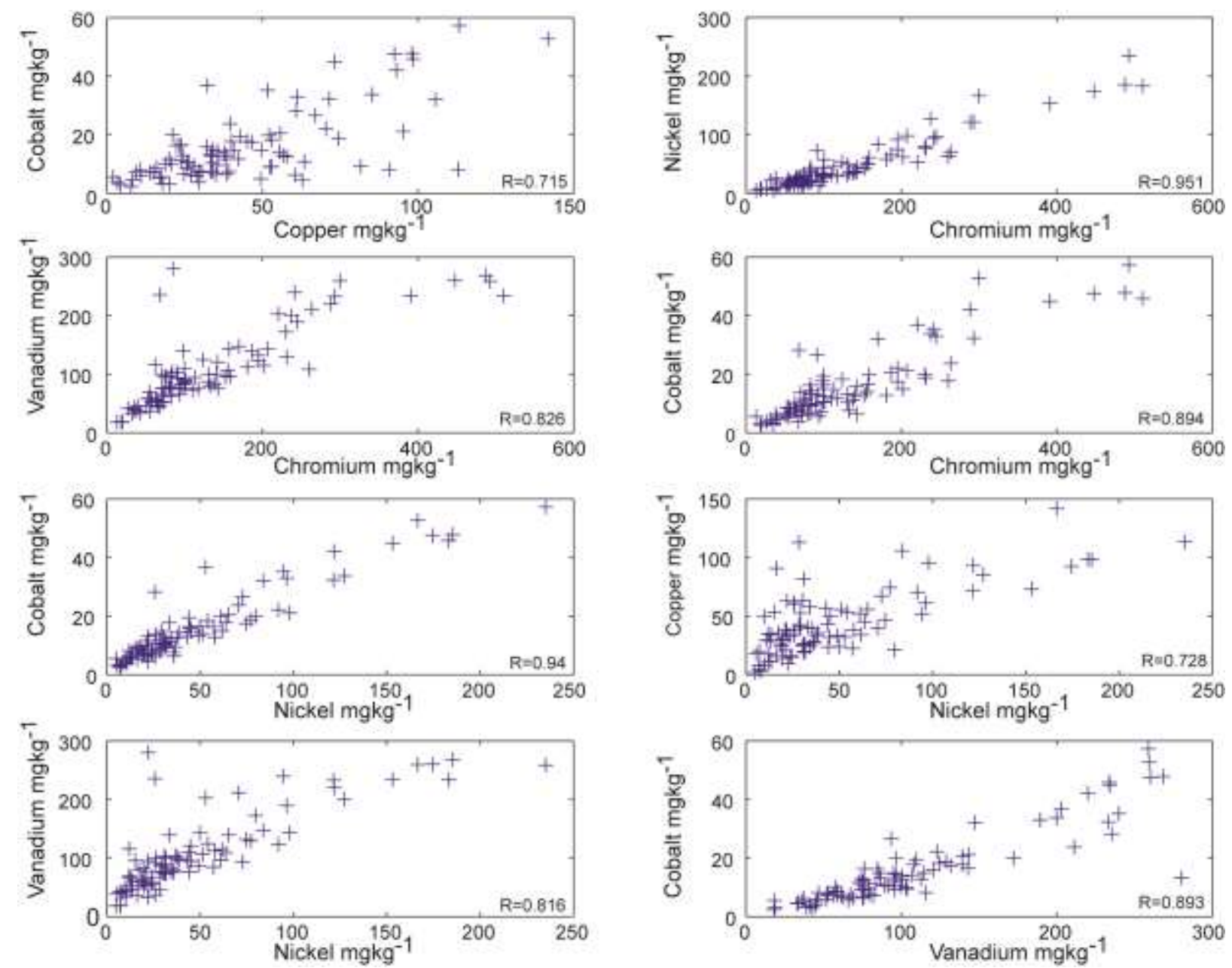

Figure 5 


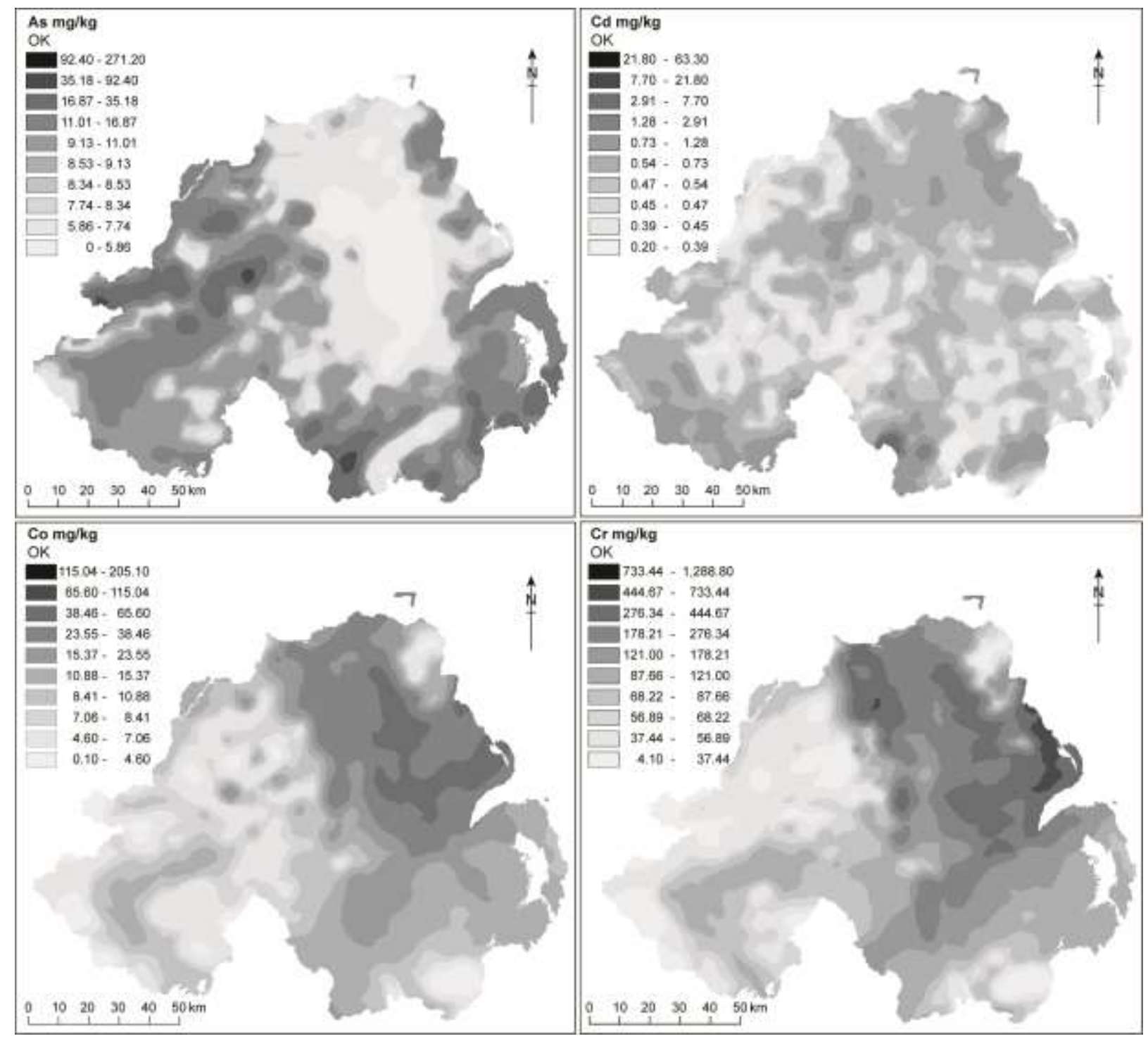

Figure 6 


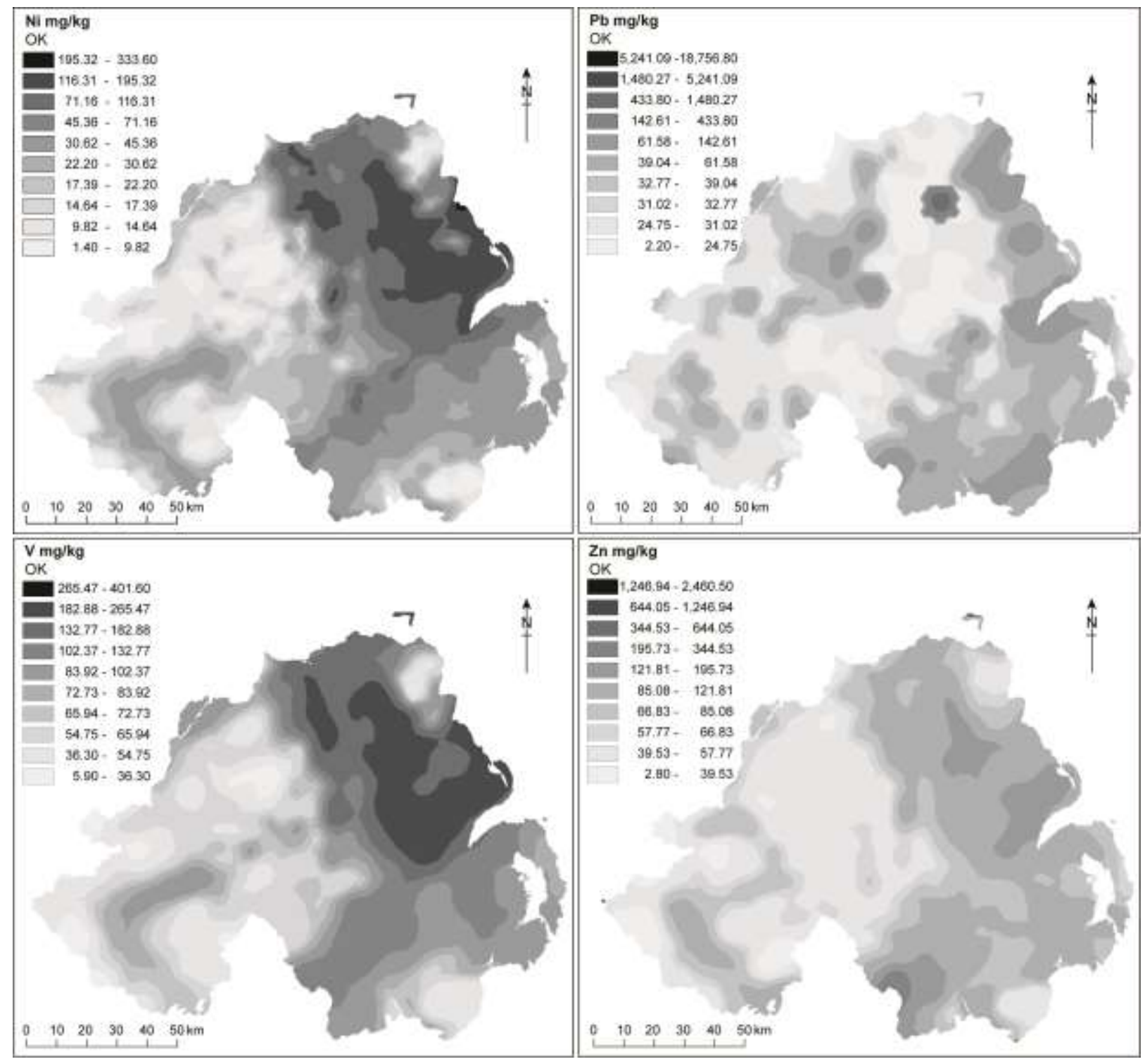

Figure 7 

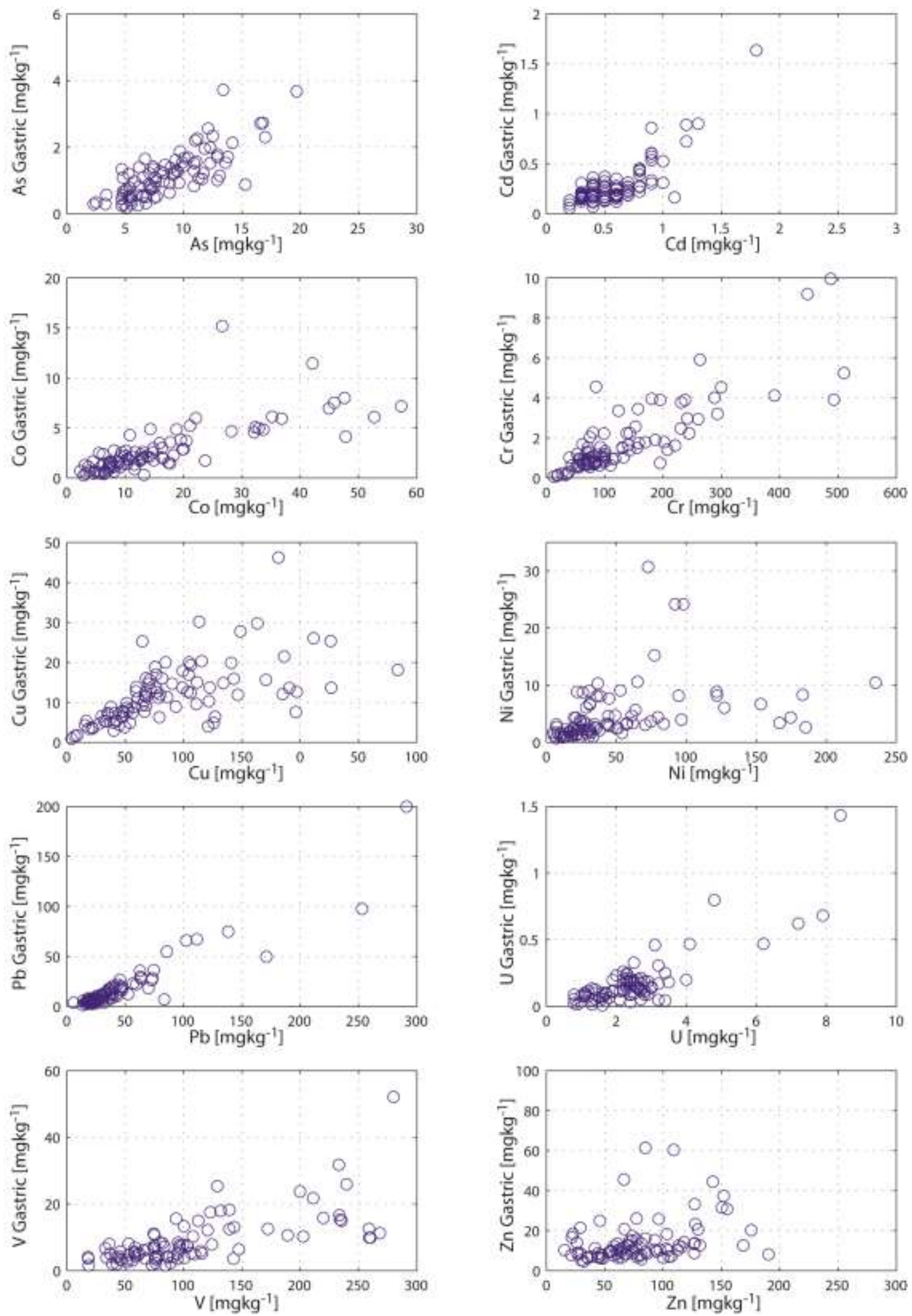

\section{Figure 8}



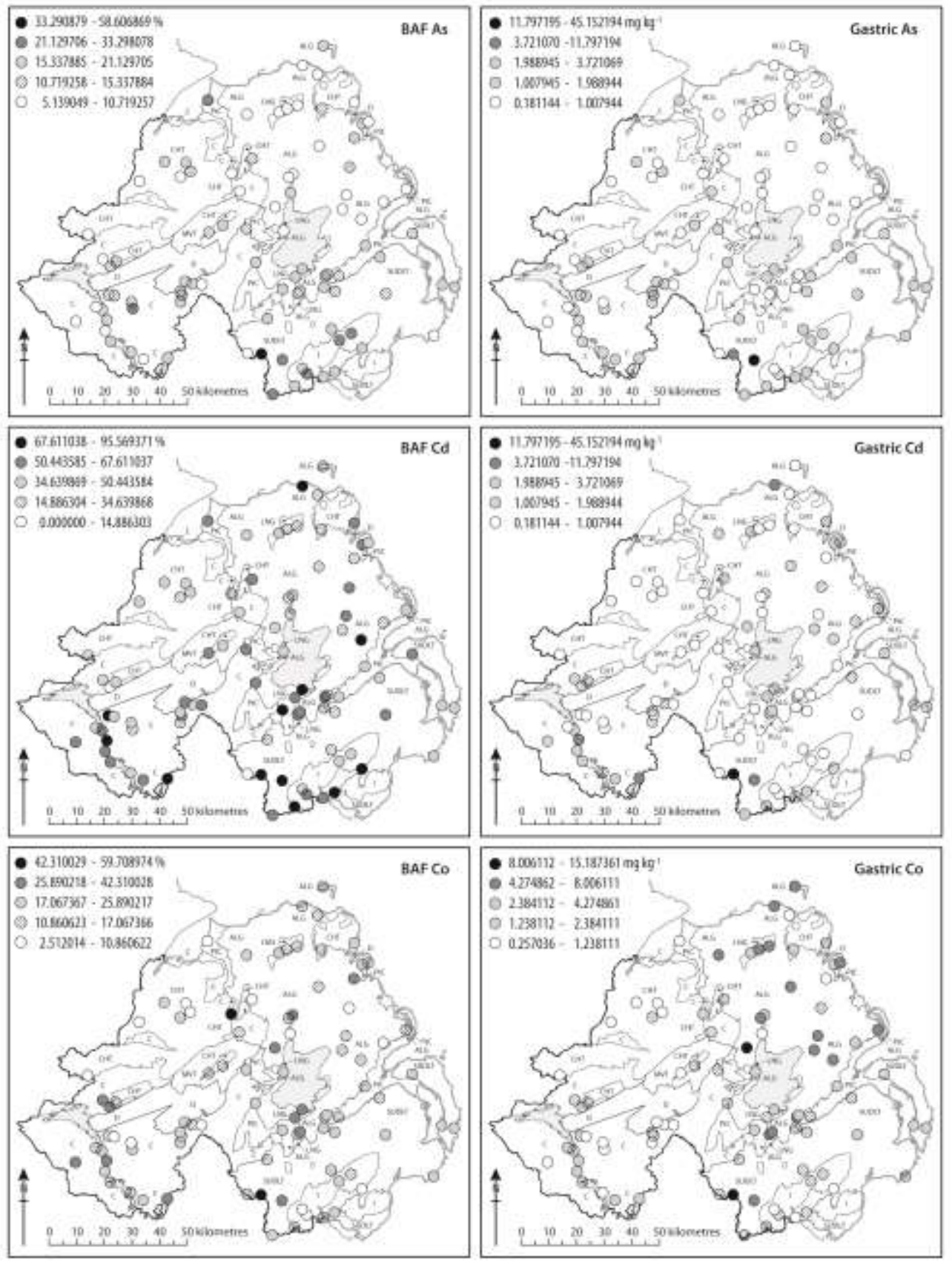

\section{Figure 9}



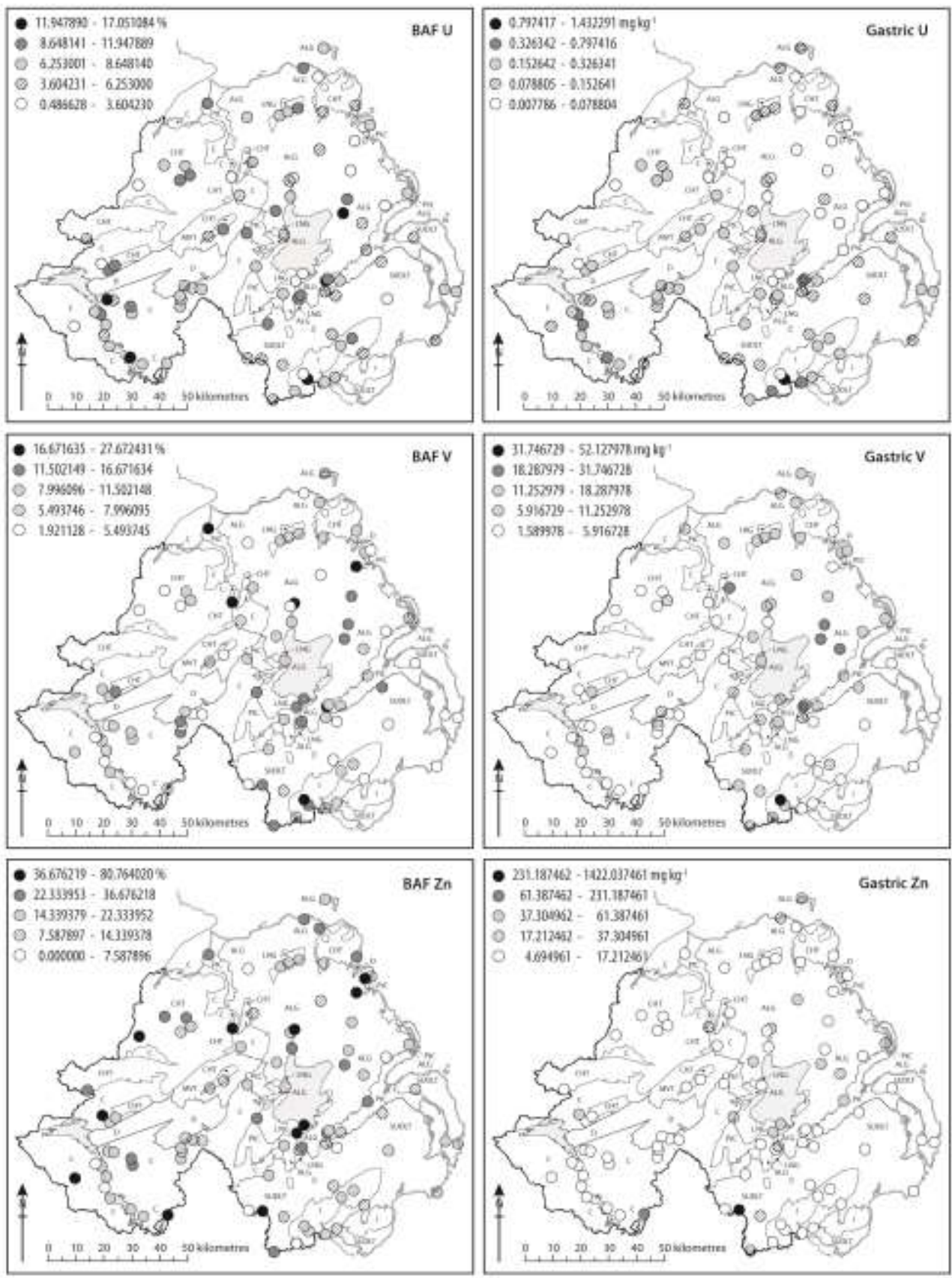

Figure 10 

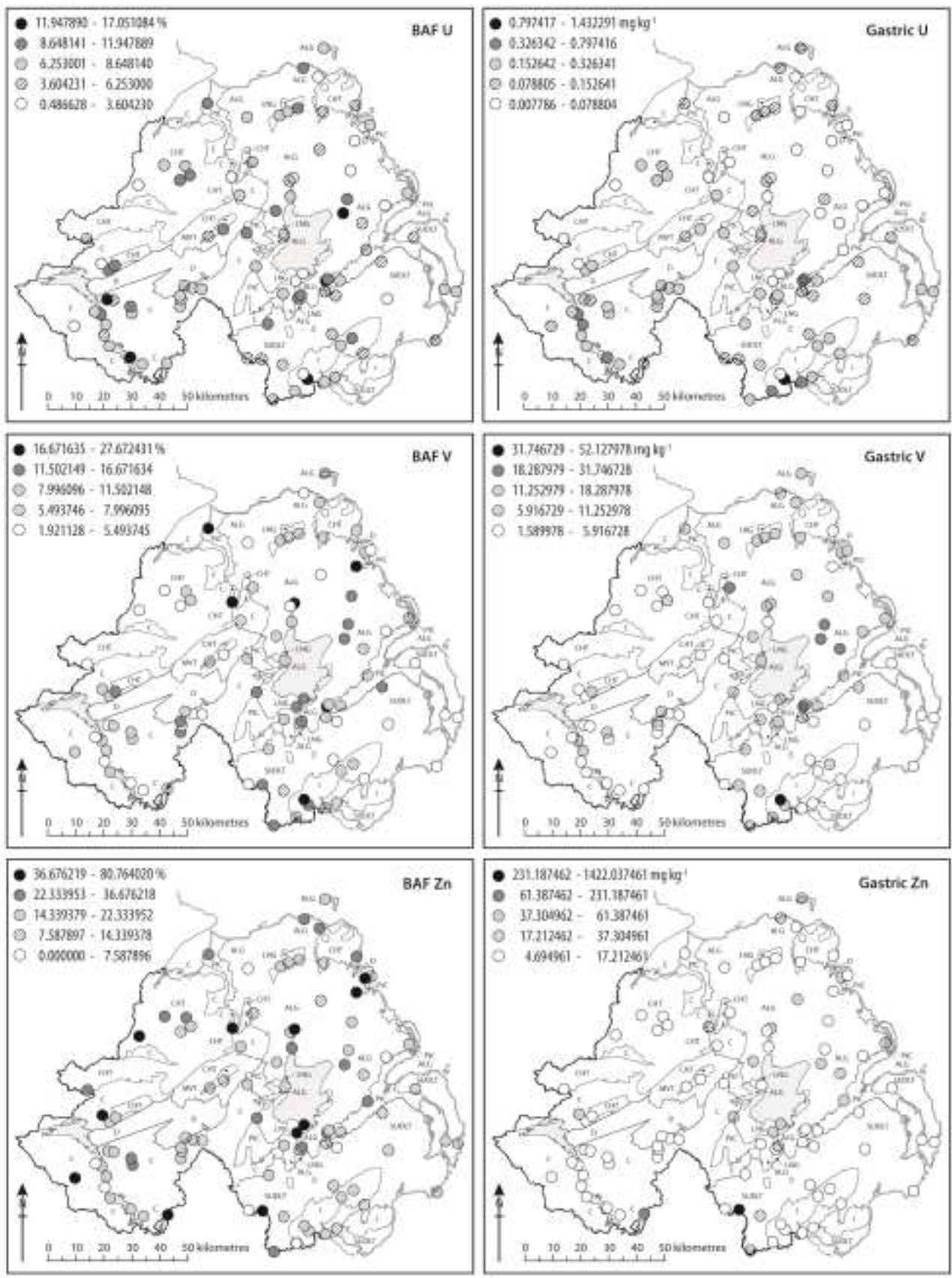

\section{Figure 11}




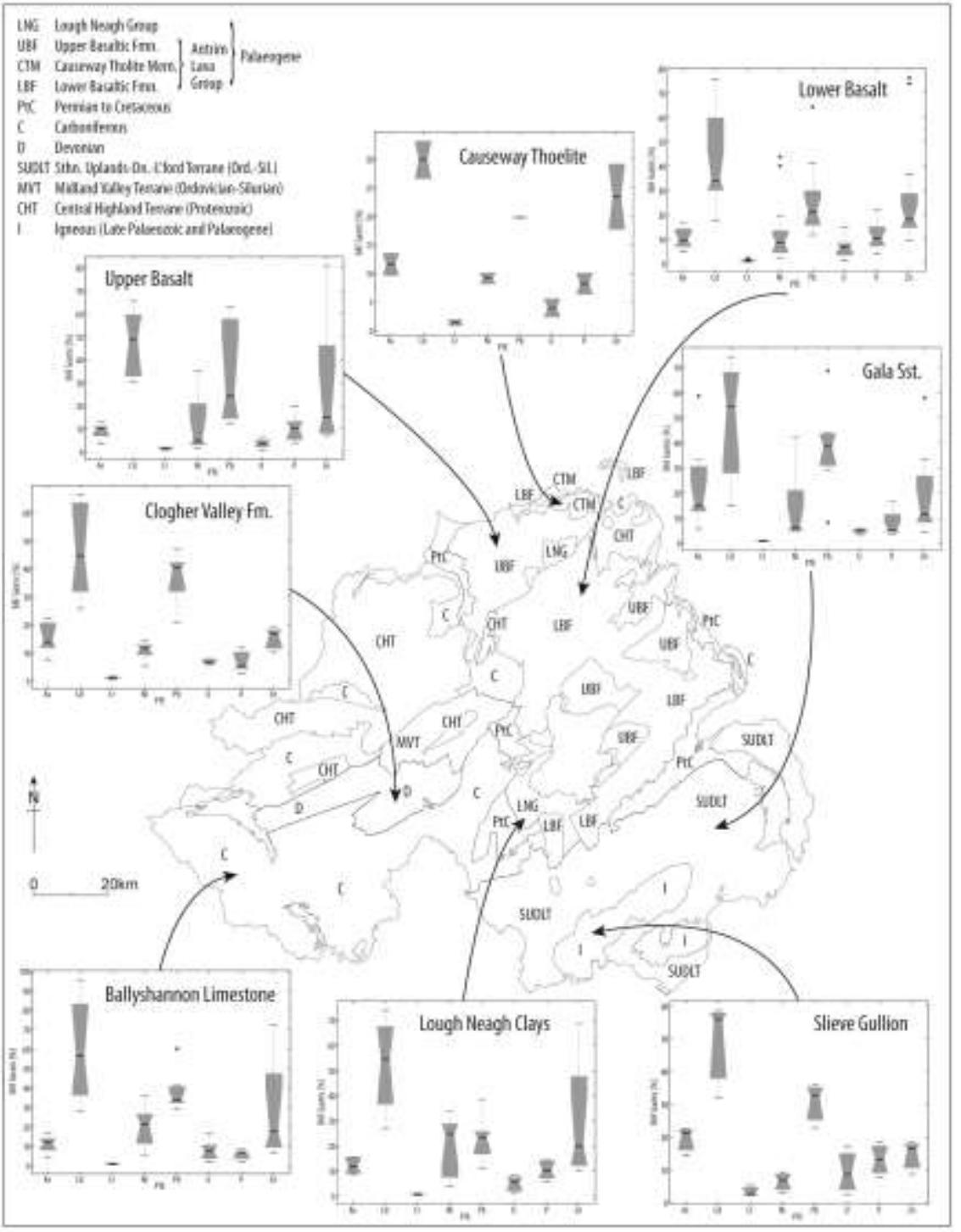

Figure 12 